\title{
Diversificación productiva y especializaciones sectoriales en Chile
}

Ignacio Rodríguez Rodríguez y

Paulina Sanhueza Martínez

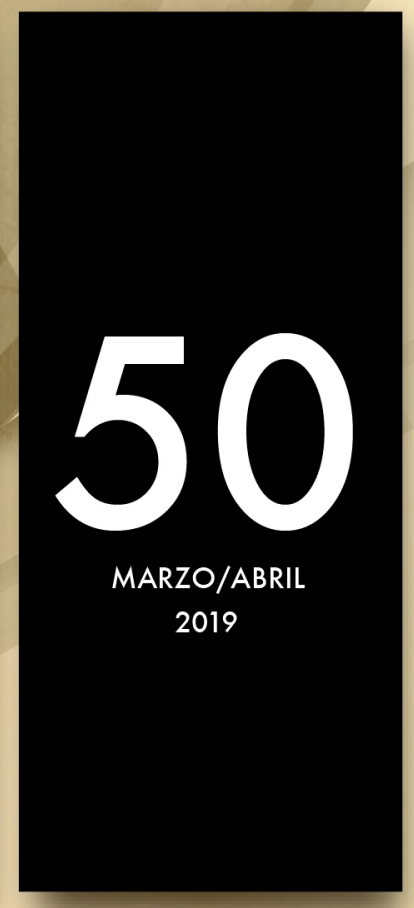

estudios regionales en
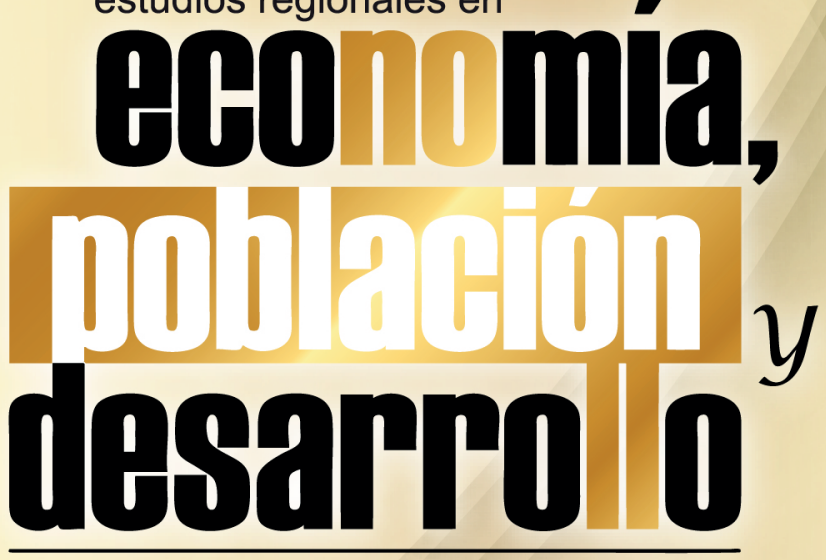

cuadernos de trabajo de la UACJ 


\title{
Diversificación productiva y especializaciones sectoriales en Chile
}

\author{
Ignacio Rodríguez Rodríguez y Paulina Sanhueza Martínez
}

UNIVERSIDAD AUTÓNOMA DE CIUDAD JUÁREZ RED IBEROAMERICANA DE ESTUDIOS DEL DESARROLLO 


\title{
UNIVERSIDAD AUTÓNOMA DE CIUDAD JUÁREZ RED IBEROAMERICANA DE ESTUDIOS DEL DESARROLLO
}

\author{
Cuerpo Académico de Estudios Regionales en \\ Economía, Población y Desarrollo
}

Universidad Autónoma de Ciudad Juárez

2018-2024

Mtro. Juan Ignacio Camargo Nassar

Rector

Mtro. Daniel Alberto Constandse Cortez

Secretario General

Mtro. Jesús Meza Vega

Director General de Comunicación Universitaria

Dra. Beatriz Araceli Díaz Torres

Coordinadora General de Investigación y Posgrado

Comité de Coordinación de la Red Iberoamericana de Estudios del Desarrollo 2018-2020

Dra. Paulina Sanhueza Martínez (Universidad de la Frontera, Chile)

Coordinadora General

Dr. Ignacio Rodríguez Rodríguez (Universidad de la Frontera, Chile)

Secretario general

Dra. Myrna Limas Hernández

(Universidad Autónoma de Ciudad Juárez, México)

Vocal de Organización

Dr. Pablo Galaso Reca (Universidad de la República, Uruguay)

Vocal de Organización

Dr. Luis Enrique Gutiérrez Casas

Director y editor de Cuadernos de Trabajo

Estudios Regionales en Economía, Población y Desarrollo

Comité editorial

Sección internacional Dra. Sofía Boza Martínez

(Universidad de Chile, Chile)

Dra. Olga Biosca Artiñano

(Glasgow Caledonian University, Reino Unido)

Dra. Ángeles Sánchez Díez

(Universidad Autónoma de Madrid, España)

Dr. Thomas Fullerton Mankin

(University of Texas at E1 Paso, Estados Unidos)

Dr. Adrián Rodríguez Miranda

(Universidad de la República, Uruguay)

Dra. Ikuho Kochi

(Kanazawa University, Japón)

Sección local

(Universidad Autónoma de Ciudad Juárez)

Dra. Myrna Limas Hernández

Dra. Rosa María García Almada

Dr. Raúl Alberto Ponce Rodríguez

Dr. Isaac Leobardo Sánchez Juárez

Dr. Héctor Alonso Barajas Bustillos

Dr. Juan Carlos Medina Guirado

Diseño de cubierta Abigail Bautista
Estudios Regionales en Economía, Población y Desarrollo. Cuadernos de Trabajo de la UACJ ISSN 2007-3739

Número 50. Marzo/Abril 2019

Diversificación productiva y especializaciones sectoriales en Chile

Ignacio Rodríguez Rodríguez y Paulina Sanhueza Martínez

Universidad Autónoma de Ciudad Juárez

Estudios Regionales en Economía, Población y Desarrollo, Cuadernos de Trabajo de la UACJ

Año 9, No. 50 marzo - abril 2019, es una publicación bimestral editada por la Universidad Autónoma de Ciudad Juárez a través del Cuerpo Académico de Estudios Regionales en Economía, Población y Desarrollo del Instituto de Ciencias Sociales y Administración. Redacción: Avenida Universidad y H. Colegio Militar, Zona Chamizal s/n., C.P. 32300, Ciudad Juárez, Chihuahua, México. Teléfonos: (656) 688-38-00, ext. 3792. Correo electrónico: igtz@uacj.mx.

Editor responsable: Luis Enrique Gutiérrez Casas. Reserva de derechos al uso exclusivo No. 04-2011-021713353900-102. ISSN 2007-3739, Impresa por Studio Los Dorados, calle Del Campanario, número 820-2, Santa Cecilia, C.P. 32350, Cd. Juárez, Chihuahua. Distribuidor: Subdirección de Gestión de Proyecto y Marketing Editorial. Ave. Plutarco Elías Calles 1210, Foviste Chamizal, C.P. 32310, Ciudad Juárez, Chihuahua.

Este número se terminó de imprimir el 15 de febrero, 2019 con un tiraje de 120 ejempares.

Los ensayos publicitarios son responsabilidad exclusiva de sus autores. Se autoriza la reproducción total o parcial bajo condición de citar la fuente.

Registrada en: EBSCO RePEC

Publicación afiliada a la Red Iberoamericana de Estudios del Desarrollo

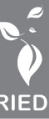

Universidad Autónoma de Ciudad Juárez

Ave Plutarco Elías Calles 1210

Foviste Chamizal, C.P. 32310

Ciudad Juárez, Chihuahua, México

www.uacj.mx

(C) Universidad Autónoma de Ciudad Juárez 


\title{
Diversificación productiva y especializaciones sectoriales en Chile
}

\author{
Ignacio Rodríguez Rodríguez * y Paulina Sanhueza Martínez **
}

\begin{abstract}
Resumen
El trabajo busca explorar las condiciones de diversificación o concentración productiva de las regiones en Chile, identificando sus especializaciones sectoriales relativas. Para lo anterior, para cada región se calculan indicadores de diversificación/concentración productiva -Índice de Herfindahl (IH)- e indicadores de especialización sectorial -Coeficiente de Especialización (CE)- utilizando fuentes de información secundaria. Los resultados indican que, en general, las regiones de Chile se muestran como territorios diversificados. En efecto, algunas regiones se especializan en actividades económicas para las cuales disfrutan de ventajas comparativas, como es el caso de las regiones mineras del norte, mientras que otras se benefician de la diversificación de su base productiva, como ocurre en la Región Metropolitana. No obstante, en algunas regiones, y a nivel nacional, existe una excesiva dependencia de los recursos naturales, lo cual puede comprometer el potencial de desarrollo de las regiones, y del país en su conjunto.
\end{abstract}

Palabras clave: Desarrollo económico regional, desarrollo endógeno, especialización productiva, Chile.

\begin{abstract}
The paper aims to explore the conditions of productive diversification/concentration in the regions of Chile, identifying its relative sectorial specializations. To do so, we estimate for every region the Herfindahl Index and the Coefficient of Specialization, both elaborated using secondary sources of information. The results show that, in general, regions in Chile are diversified territories. Indeed, some regions specialize in economic activities in which they have comparative advantages, such is the case of the mineral regions in the north of the country, while others benefit from a productive structure diversified, as occurs in the Metropolitan Region. Nevertheless, in some regions, and at a national level, there is an overdependence on natural resources, which could compromise the development potential of the regions as well as of the country as a whole.
\end{abstract}

Keywords: Regional economic development, endogenous development, productive specialization, Chile. JEL Classification: R11, R58, O18.

- Recibido en: Febrero de 2019.

- Aprobado en: Marzo 2019.

* Académico del Departamento de Ciencias Sociales de la Facultad de Educación, Ciencias Sociales y Humanidades de la Universidad de La Frontera, Chile. Integrante de la Red Iberoamericana de Estudios del Desarrollo (RIED) y del Grupo de Estudios sobre las Transformaciones de la Economía Mundial (GETEM). Correo electrónico: ignacio.rodríguez@ufrontera.cl.

** Académica del Departamento de Administración y Economía de la Facultad de Ciencias Jurídicas y Empresariales de la Universidad de La Frontera, Chile. Integrante fundadora de la Red Iberoamericana de Estudios del Desarrollo (RIED). Correo electrónico: paulina.sanhueza@ufrontera.cl. 


\section{$\rightarrow$ 1. Introducción. ${ }^{1}$}

El desarrollo de las economías y la mayor calidad de vida que ello ha generado en los individuos ha hecho centrar la atención, durante las últimas cinco décadas, en los mecanismos generadores del desarrollo y en los obstáculos para alcanzarlo, surgiendo así un nuevo paradigma en la teoría del desarrollo económico: el desarrollo endógeno. Las diversas definiciones que se le han dado, coinciden en presentarlo como un enfoque basado en el aprovechamiento de los recursos y potencialidades endógenas de un territorio, entendidos como punto de partida para un nuevo tipo de desarrollo centrado en lo local. Vázquez Barquero (1999, p. 32) sostiene que "el desarrollo endógeno puede entenderse como un proceso de crecimiento económico y cambio estructural, liderado por la comunidad local utilizando el potencial de desarrollo, que conduce a la mejora del nivel de vida de la población local". En este sentido, la diferencia en la dinámica de las regiones y territorios, se explica, en la interacción de cuatro mecanismos o fuerzas del desarrollo endógeno, fuerzas que impulsan y moldean dicho desarrollo (Vázquez Barquero, 1993, 1999, 2002; Vergara, 2004). Estos mecanismos, definidos por Vázquez Barquero (2005, 2008), son: la organización flexible de la producción; la difusión de las innovaciones y el conocimiento; el cambio y adaptación de las instituciones; y el desarrollo policéntrico del territorio.

Específicamente, la organización flexible de la producción, se constituye en la fuerza central del desarrollo económico, dado que las empresas y las relaciones entre ellas afectan directamente al comportamiento de la productividad y, por tanto, a los procesos de crecimiento y cambio estructural de las economías regionales o locales. Resulta obvio el papel fundamental que juegan las empresas como agentes económicos en la creación de puestos de trabajo y de riqueza, siendo estas unidades económicas las piezas claves para generar crecimiento económico y empleo en el territorio (Alburquerque, 2002, 2004), y su forma de relacionarse es un aspecto trascendental para hacer más eficientes, rentables y productivas a las inversiones.

Este enfoque, por tanto, resulta interesante para explicar las diferencias en términos de desarrollo económico entre las regiones, centrándose en el análisis de las empresas y, a través de ello, en la potencialidad de los territorios para desarrollar tejidos productivos locales competitivos. Es así que, el objetivo de este trabajo es explorar las condiciones de diversificación o concentración productiva de las regiones en Chile, identificando sus especializaciones sectoriales relativas.

\footnotetext{
${ }^{1}$ Este trabajo forma parte de los resultados del proyecto de investigación "Estudio de desarrollo productivo regional comparado en Chile, El Salvador, Paraguay y Uruguay. El rol de la cooperación entre empresas: evidencia e implicaciones para la política de desarrollo productivo", financiado por el fondo concursable TTI's Opportunity Fund, de la Think Tank Initiative del International Development Research Centre (IDRC) de Canadá. Los autores queremos agradecer al equipo del Instituto de Economía (IECON) de la Universidad de la República, Uruguay, especialmente al Dr. Adrián Rodríguez Miranda y al Dr. Pablo Galaso, por proporcionar los lineamientos metodológicos del estudio, los cuales se han utilizado para la elaboración de este artículo. Asimismo, agradecemos a Diego Robles por la ayuda brindada en la recolección de información para la estimación de los indicadores y la elaboración de los mapas.
} 


\section{Antecedentes generales de la economía chilena.}

Chile es un país que asienta su territorio en tres continentes: América del Sur, Antártida y Oceanía. La mayor parte de su territorio está situado en la parte occidental y meridional de Sudamérica, pero también se prolonga hacia el continente antártico y alcanza la Polinesia con la Isla de Pascua. De esta forma, la superficie de Chile (americano, antártico e insular) es de $2.006 .096 \mathrm{~km} 2$.

Administrativamente el país se divide en quince regiones, 54 provincias y 346 comunas (ver Mapa 1).

Según las cifras del censo de población del año 2017, en Chile residen 17.574.003 habitantes $^{2}$. Aunque la densidad de la población promedio es de 8,8 habitantes por km2, en Chile hay una alta concentración demográfica: el 41\% de la población del país vive en la Región Metropolitana de Santiago y el 74\% entre Valparaíso y Bío Bío (Tabla 1).

En cuanto al PIB per cápita, como medida de la capacidad productiva de las regiones, las que presentan un valor superior a la media del país son Antofagasta, Tarapacá, Atacama y la Región Metropolitana de Santiago, es decir, las regiones del norte del país en las que la minería es el sector dominante, junto con la Región Metropolitana, donde se encuentra la capital del país, en la que predominan la industria y los servicios financieros. En cambio, las regiones con menor PIB per cápita son las del centro y sur del país (La Araucanía, Los Ríos, Los Lagos, Maule y Bío Bío), en las que la agricultura, la actividad forestal y la pesca son los sectores dominantes (Tabla 2).

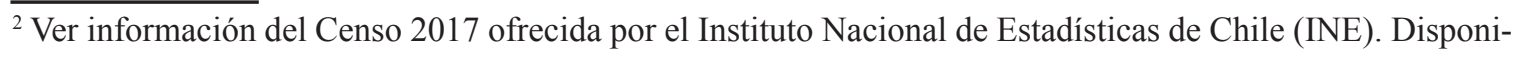
ble en: http://www.censo2017.cl/ [Consulta: 2017, 23 de diciembre]. 


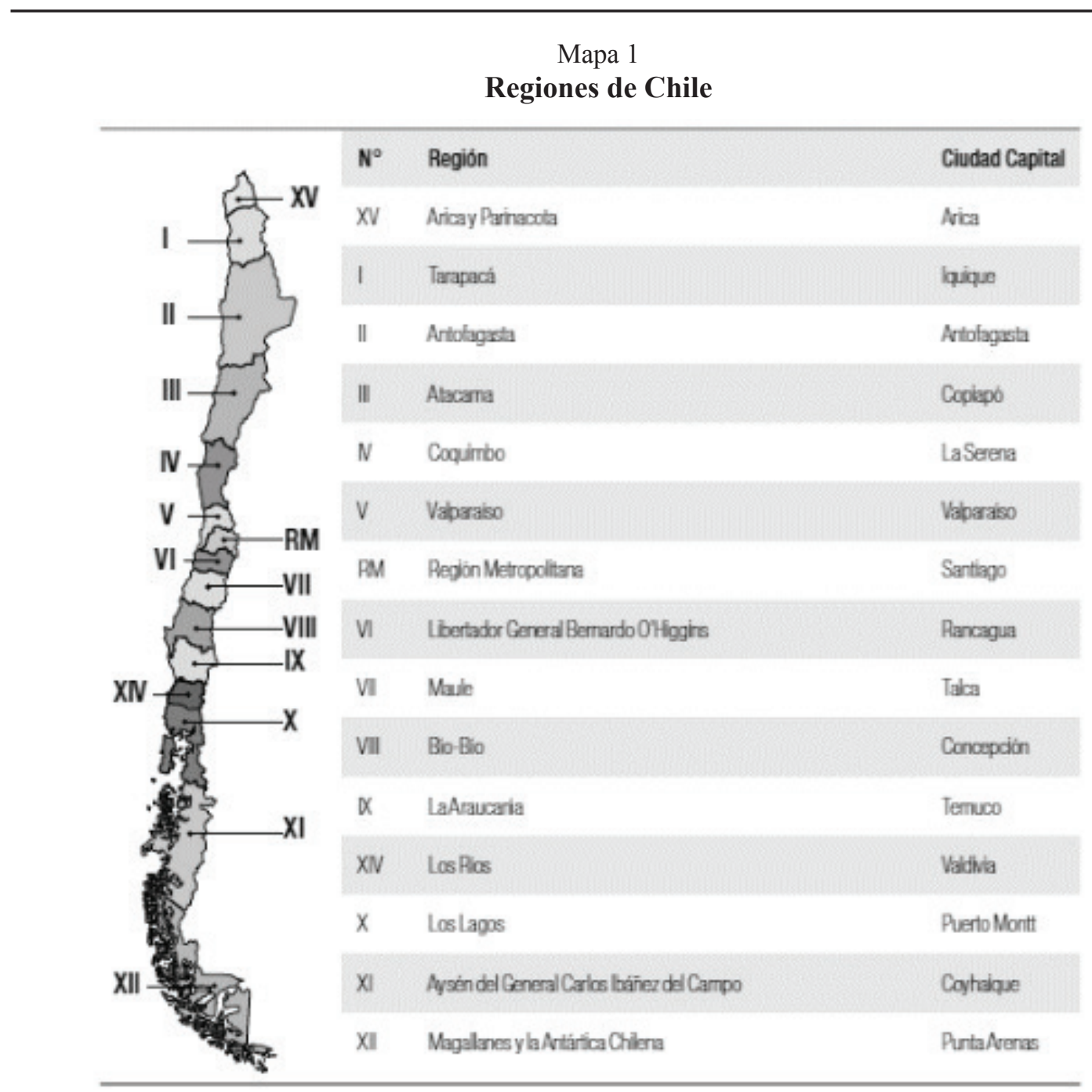

Fuente: OCDE (2009, p. 6).

Respecto al mercado de trabajo, la tasa de desempleo, para 2015, muestra que Los Lagos (región del sur del país), junto con Aysén y Magallanes (regiones australes) son los territorios que presentan indicadores de desempleo más bajos (3,5\% o menor); mientras que las regiones con las tasas de desempleo más altas en 2015 son Bío Bío, Coquimbo y Tarapacá, todas ellas por encima del 7\%. Si se observa el porcentaje del empleo privado en el total de ocupación, Los Lagos, la Región Metropolitana, Maule y Magallanes destacan por ser las regiones que muestran en el año 2016 una mayor contribución del sector privado al empleo (todas ellas con valores cercanos al 90\%), lo cual es una medida del dinamismo de dicho sector y de menor dependencia de la economía regional respecto del empleo público. En contraste, Tarapacá, Atacama, Coquimbo y Antofagasta, con porcentajes de empleo público en torno al 23\%, son las regiones más dependientes del empleo público en el país, cuyo promedio nacional representa un $14 \%$. 
Tabla 1

Composición poblacional y territorial de Chile por región

\begin{tabular}{|c|c|c|c|c|}
\hline Zona & Región & $\begin{array}{c}\text { Superficie } \\
\left(\mathrm{km}^{2}\right)\end{array}$ & $\begin{array}{c}\text { Población } \\
\text { (hab.) }\end{array}$ & $\begin{array}{c}\text { Densidad de } \\
\text { población } \\
\left(\mathrm{hab} / \mathrm{km}^{2}\right)\end{array}$ \\
\hline \multirow{3}{*}{ Norte grande } & Arica y Parinacota & $16.873,3$ & 226.068 & 13,4 \\
\hline & Tarapacá & $42.225,8$ & 330.558 & 7,8 \\
\hline & Antofagasta & $126.049,1$ & 607.534 & 4,8 \\
\hline \multirow{2}{*}{ Norte chico } & Atacama & $75.176,2$ & 286.168 & 3,8 \\
\hline & Coquimbo & $40.579,9$ & 757.586 & 18,7 \\
\hline \multirow{4}{*}{ Central } & Valparaíso & $16.396,1$ & 1.815 .902 & 110,8 \\
\hline & Metropolitana & $15.403,2$ & 7.112 .808 & 461,8 \\
\hline & O'Higgins & $16.387,0$ & 914.555 & 55,8 \\
\hline & Maule & $30.296,1$ & 1.044 .950 & 34,5 \\
\hline \multirow{4}{*}{ Sur } & Bir Bie & $37.068,7$ & 2.037 .414 & 55,0 \\
\hline & La Araucanía & $31.842,3$ & 957.224 & 30,1 \\
\hline & Los Ríos & $18.429,5$ & 384.837 & 20,9 \\
\hline & Los Lagos & $48.583,6$ & 828.708 & 17,1 \\
\hline \multirow[b]{2}{*}{ Austral } & Aysén & $108.494,4$ & 103.158 & 1,0 \\
\hline & $\begin{array}{l}\text { Magallanes y Antártica } \\
\text { chilena* }\end{array}$ & $1.382 .291,1$ & 166.533 & 0,1 \\
\hline Total & País_ & 2.006 .096 .3 & 17.574 .003 & 8.8 \\
\hline
\end{tabular}

Notas: (*) La superficie en la parte americana es de 132.291,1 km2 mientras que 1.250.000 km2 corresponden a territorio antártico. Fuente: Elaboración propia. Datos provenientes del INE.

Tabla 2

Indicadores de actividad económica de Chile por región

\begin{tabular}{lrrrr}
\hline Región & $\begin{array}{c}\text { PIB per cápita, } \\
\mathbf{2 0 1 5} \text { (pesos) } \\
\text { (1) }\end{array}$ & $\begin{array}{c}\text { Tasa de } \\
\text { desempleo, 2015 } \\
\text { (2) }\end{array}$ & $\begin{array}{c}\text { Empleo privado } \\
\text { en el total (\%), } \\
\mathbf{2 0 1 6}(2)\end{array}$ & $\begin{array}{c}\text { MIPYMES cada } \\
\mathbf{1 0 . 0 0 0} \text { hab., 2015 } \\
\text { (3) }\end{array}$ \\
\hline Arica y Parinacota & 2.911 .678 & $5.3 \%$ & $80,0 \%$ & 546 \\
Tarapaca & 8.047 .279 & $7,3 \%$ & $75,6 \%$ & 507 \\
Antofagasta & 19.016 .191 & $6,7 \%$ & $77,5 \%$ & 441 \\
Atacama & 7.413 .417 & $5,6 \%$ & $75,6 \%$ & 460 \\
Coquimbo & 4.237 .543 & $7,4 \%$ & $77,0 \%$ & 459 \\
Valparaíso & 4.879 .358 & $6,9 \%$ & $84,2 \%$ & 487 \\
Metropolitana & 7.241 .567 & $6,2 \%$ & $90,5 \%$ & 515 \\
O'Higgins & 5.358 .394 & $5,5 \%$ & $81,2 \%$ & 529 \\
Maule & 3.560 .237 & $5,7 \%$ & $89,6 \%$ & 580 \\
Bís Bí & 3.882 .207 & $7,5 \%$ & $79,6 \%$ & 442 \\
La Araucaní & 2.512 .994 & $6,9 \%$ & $88,0 \%$ & 444 \\
Los Ríos & 3.380 .002 & $4,5 \%$ & $86,8 \%$ & 481 \\
Los Lagos & 3.529 .815 & $3,1 \%$ & $92,0 \%$ & 557 \\
Aysén & 5.524 .167 & $3,5 \%$ & $87,4 \%$ & 659 \\
Magallanes & 5.576 .050 & $3,5 \%$ & $89,1 \%$ & 624 \\
\hline Pais & 6.597 .833 & $6,2 \%$ & $86,3 \%$ & 501 \\
\hline
\end{tabular}

Fuente: Elaboración propia. Datos provenientes de: (1) Banco Central de Chile (BCCh); (2) Instituto Nacional de Estadisticas (INE); (3) Servicio de Impuestos Internos (SII).

Finalmente, la densidad de MIPYMES, como medida del desarrollo empresarial regional, muestra que las regiones que presentan los mayores valores son Aysén (659 MIPYMES cada 10.000 habitantes), Magallanes (624), Maule (580) y Los Lagos (557). Al contrario, las que presentan valores más bajos son Antofagasta (441), Bío Bío (442), La Araucanía (444) y Coquimbo (459). 


\section{O 3. Especializaciones productivas regionales en Chile.}

A continuación se analizan las condiciones de diversificación o concentración productiva de las regiones de Chile. Para ello, en primer lugar, se presentan las especializaciones sectoriales a escala nacional. Posteriormente, se analizan la diversificación productiva y las especializaciones sectoriales por región. Finalmente, se realizan algunas consideraciones generales sobre la diversificación productiva en las regiones de Chile.

\subsection{Especializaciones sectoriales a escala nacional.}

En este apartado se presenta brevemente un panorama de la capacidad productiva y exportadora del país. Posteriormente, en el siguiente apartado, se profundiza en el análisis regional, presentando la contribución de las regiones de Chile a esa capacidad productiva nacional.

Para realizar la identificación de los principales sectores productivos de Chile, se analizan dos aspectos: (i) la capacidad exportadora de los sectores económicos y (ii) la participación de los sectores económicos en la producción nacional.

En el año 2017, las exportaciones chilenas tuvieron un buen desempeño, tras registrar USD 69.320 millones, experimentando una expansión respecto al año anterior de 14\%. Este dinamismo obedeció al alza de las exportaciones mineras e industriales, que compensaron la caída de las exportaciones en productos silvoagropecuarios y pesqueros. Las exportaciones chilenas a socios con acuerdo comercial crecieron un $12 \%$ con respecto al año 2016, mientras que las exportaciones hacia el resto de las economías aumentaron un $24 \%$ (DIRECON, 2018). En este sentido, los principales destinos de las exportaciones chilenas son China (27,5\%), Estados Unidos (14,4\%), la Unión Europea (12,7\%), Japón (9,3\%), Mercosur (7,5\%), Corea del Sur (6,2\%) y Alianza del Pacífico (5,3\%) (DIRECON, 2018).

Los principales rubros de exportación son la minería, los alimentos, las bebidas, el sector frutícola, la celulosa y la maquinaria y equipos industriales. Las exportaciones de cobre representan el 50\% de las exportaciones totales del país en el año 2017. Otros productos importantes en términos de exportación son el salmón (6\%), el vino (2\%), la uva (2\%) y la celulosa de eucaliptus $(2 \%)$ y conífera (2\%) (Tabla 3). Luego se encuentran otros productos mineros (fundamentalmente, hierro, litio, y oro), frutas (manzanas, cerezas, paltas y arándanos), alimentos (moluscos y crustáceos, trucha), forestales (madera), químicos (molibdeno, abonos) y productos metálicos (maquinaria y equipos, material de transporte), que configuran el $34 \%$ restante. 


\begin{tabular}{|c|c|c|c|c|}
\hline \multicolumn{5}{|c|}{$\begin{array}{c}\text { Tabla } 3 \\
\text { Principales rubros de exportación de Chile } \\
2016-2017\end{array}$} \\
\hline \multirow{2}{*}{ Rubro } & \multicolumn{2}{|c|}{ Monto (millones de USD) } & \multicolumn{2}{|c|}{ Participación (\%) } \\
\hline & 2016 & 2017 & 2016 & 2017 \\
\hline Cobre & 28.073 & 34.868 & $46 \%$ & $50 \%$ \\
\hline Salmón & 3.465 & 4.159 & $6 \%$ & $6 \%$ \\
\hline Vino embotellado & 1.545 & 1.634 & $3 \%$ & $2 \%$ \\
\hline Uva & 1.4 & 1.231 & $2 \%$ & $2 \%$ \\
\hline Celulosa de eucaliptus & 1.011 & 1.191 & $2 \%$ & $2 \%$ \\
\hline Maquinaria y equipos & 1.175 & 1.164 & $2 \%$ & $2 \%$ \\
\hline Celulosa de conifera & 1.153 & 1.141 & $2 \%$ & $2 \%$ \\
\hline Otros & 22.912 & 23.842 & $38 \%$ & $34 \%$ \\
\hline Total & 60.733 & 69.23 & $100 \%$ & $100 \%$ \\
\hline
\end{tabular}

Fuente: Elaboración propia. Datos provenientes de Banco Central de Chile. Disponible en: https://si3.bcentral.cl/Sietel secure/cuadros/home.aspx [Consulta: 2018, 21 de mayo].

Otro aspecto para valorar la importancia de los sectores productivos es su contribución al PIB nacional. En la Tabla 4 se muestra la contribución de los sectores económicos al PIB de Chile en los últimos cinco años. Como se puede observar, en promedio, los sectores que presentan mayor importancia relativa son: los servicios personales $(12,3 \%)$, la minería e industria manufacturera $(11,6 \%$ cada uno), los servicios empresariales $(11,2 \%)$ y el comercio $(10 \%)$. Por otro lado, en los últimos cinco años se puede destacar que la minería y la industria manufacturera registran una disminución paulatina, mientras que los servicios personales aumentan de manera progresiva durante ese período.

En relación a la industria manufacturera, en la Tabla 5 se puede observar el peso relativo de las diferentes actividades del sector durante el período 2015-2017. En la generación del PIB de la industria manufacturera en el 2017, se destaca como principal sector los alimentos, con una participación del $27 \%$, seguido de los productos metálicos, maquinaria y equipos (17\%), química, caucho y plástico (14\%) y bebidas y tabaco (12\%). Dentro de la industria de alimentos, la principal contribución proviene de la industria del salmón, siendo uno de los principales productos chilenos de exportación. La producción de maquinaria y equipos y productos químicos, caucho y plástico tiene como destino el mercado interno y la exportación. Por otra parte, dentro de bebidas y tabaco, se encuentra todo lo relacionado con la industria vitivinícola que, en general, está orientada a los mercados internacionales, aunque también se encuentra presente en el mercado interno. 
Tabla 4

PIB de Chile: participación por sectores de actividad

2013-2017

\begin{tabular}{|c|c|c|c|c|c|c|}
\hline Sectores & 2013 & 2014 & 2015 & 2016 & 2017 & Promedio \\
\hline Agropecuario-silvicola & $3,2 \%$ & $3,0 \%$ & $3,2 \%$ & $3,3 \%$ & $3,2 \%$ & $3,2 \%$ \\
\hline Pesca & $0,5 \%$ & $0,6 \%$ & $0,5 \%$ & $0,5 \%$ & $0,6 \%$ & $0,5 \%$ \\
\hline Minería & $12,0 \%$ & $12,1 \%$ & $11,7 \%$ & $11,2 \%$ & $10,8 \%$ & $11,6 \%$ \\
\hline Industria manufacturera & $12,1 \%$ & $11,8 \%$ & $11,6 \%$ & $11,2 \%$ & $11,2 \%$ & $11,6 \%$ \\
\hline Electricidad, gas y agua & $2,8 \%$ & $2,9 \%$ & $2,9 \%$ & $2,9 \%$ & $3,0 \%$ & $2,9 \%$ \\
\hline Construcción & $7,1 \%$ & $6,9 \%$ & $7,0 \%$ & $7,1 \%$ & $6,9 \%$ & $7,0 \%$ \\
\hline Comercio & $9,9 \%$ & $10,0 \%$ & $9,9 \%$ & $10,1 \%$ & $10,3 \%$ & $10,0 \%$ \\
\hline Restaurantes y hoteles & $2,0 \%$ & $2,1 \%$ & $2,1 \%$ & $2,1 \%$ & $2,1 \%$ & $2,1 \%$ \\
\hline Transporte & $5,2 \%$ & $5,2 \%$ & $5,4 \%$ & $5,5 \%$ & $5,5 \%$ & $5,4 \%$ \\
\hline Comunicaciones & $3,4 \%$ & $3,4 \%$ & $3,6 \%$ & $3,6 \%$ & $3,7 \%$ & $3,5 \%$ \\
\hline Servicios financieros & $5,5 \%$ & $5,5 \%$ & $5,6 \%$ & $5,8 \%$ & $5,9 \%$ & $5,7 \%$ \\
\hline Servicios empresariales & $11,7 \%$ & $11,5 \%$ & $11,3 \%$ & $10,9 \%$ & $10,5 \%$ & $11,2 \%$ \\
\hline Servicios de vivienda & $7,8 \%$ & $8,0 \%$ & $8,0 \%$ & $8,2 \%$ & $8,3 \%$ & $8,0 \%$ \\
\hline Servicios personales & $11,9 \%$ & $12,0 \%$ & $12,1 \%$ & $12,5 \%$ & $12,8 \%$ & $12,3 \%$ \\
\hline Administración pública & $4,9 \%$ & $4,9 \%$ & $5,0 \%$ & $5,1 \%$ & $5,1 \%$ & $5,0 \%$ \\
\hline PIB $\%$ & $100,0 \%$ & $100,0 \%$ & $100,0 \%$ & $100,0 \%$ & $100,0 \%$ & - \\
\hline PIB (millones de USD) $(*)$ & 278.538 & 246.157 & 219.406 & 214.772 & 227.203 & - \\
\hline
\end{tabular}

Nota (*): Calculado con el dólar observado anual ofrecido por el Banco Central de Chile.

Fuente: Elaboración propia. Datos provenientes de Banco Central de Chile. Disponible en: https://si3.bcentral.cl/Siete/ secure/cuadros/home.aspx [Consulta: 2018, 21 de mayo].

Tabla 5

PIB de la industria manufacturera por sectores de actividad

2015-2017

\begin{tabular}{lrrr}
\hline \multicolumn{1}{c}{ Sectores } & $\mathbf{2 0 1 5}$ & $\mathbf{2 0 1 6}$ & $\mathbf{2 0 1 7}$ \\
\hline Alimentos & $25,8 \%$ & $26,4 \%$ & $27,3 \%$ \\
Productos metálicos, maquinaria y equipos y otros & $16,4 \%$ & $16,7 \%$ & $17,2 \%$ \\
Química, caucho y plástico & $14,8 \%$ & $14,6 \%$ & $14,4 \%$ \\
Bebidas y tabaco & $14,1 \%$ & $13,0 \%$ & $12,4 \%$ \\
Refinación de petróleo & $7,6 \%$ & $7,6 \%$ & $7,8 \%$ \\
Celulosa, papel e imprentas & $8,0 \%$ & $7,9 \%$ & $7,6 \%$ \\
Maderas y muebles & $5,4 \%$ & $5,6 \%$ & $5,5 \%$ \\
Minerales no metálicos y metálica básica & $5,5 \%$ & $5,8 \%$ & $5,3 \%$ \\
Textil, prendas de vestir, cuero y calzado & $2,4 \%$ & $2,5 \%$ & $2,5 \%$ \\
Industria manufacturera (\%) & $100 \%$ & $100 \%$ & $100 \%$ \\
Industria manufacturera (millones de USD) $(*)$ & 23.324 & 22.035 & 23.313 \\
\hline
\end{tabular}

Nota (*): Calculado con el dólar observado anual ofrecido por el Banco Central de Chile.

Fuente: Elaboración propia. Datos provenientes de Banco Central de Chile. Disponible en: https://si3.bcentral.cl/ Siete/secure/cuadros/home.aspx [Consulta: 2018, 21 de mayo]. 


\subsection{Diversificación productiva y especializaciones sectoriales por región.}

En este apartado, por un lado, se caracterizan a las economías regionales según su grado de diversificación o concentración de las actividades productivas. Por otro lado, se analizan cuáles son las especializaciones sectoriales por región, dando cuenta de cómo se materializan en el territorio los esfuerzos y capacidades productivas que antes se analizaron a escala nacional.

\subsubsection{Diversificación productiva.}

Para analizar la diversificación o concentración productiva de los territorios, se utiliza el Índice de Herfindahl (IH), el cual se calcula a partir de la siguiente fórmula:

$$
I H_{J}=\sum_{i=1}^{n}\left(\frac{x_{i j}}{x_{J}}\right)^{2}
$$

\section{Donde:}

- $\quad X_{i j}=$ cantidad de empresas en el sector $i$ en el territorio $j$

- $\quad X_{J}=$ cantidad de empresas en el territorio $j$

- Sectores productivos $i=1, \ldots, n$.

El IH cuantifica el grado de especialización o diversificación productiva de un territorio. Su valor se sitúa entre 1 y $1 / \mathrm{n}$, siendo n la cantidad de sectores identificados en la economía. Si en un territorio el IH muestra un valor cercano a 1, significa que hay una alta especialización en pocos sectores, por lo que hay potencialmente un "efecto distrito" (economías marshallianas). En cambio, si muestra valores bajos y cercanos a $1 / \mathrm{n}$, significa que el territorio tiene gran diversidad de sectores, por lo que hay potenciales economías de aglomeración urbana.

En este sentido, lo normal es que en áreas metropolitanas y grandes ciudades -es decir, en territorios densamente poblados-, el IH muestre valores bajos, puesto que en general cuentan con economías más diversificadas. Ahora bien, para interpretar adecuadamente el indicador, conviene señalar que el IH únicamente informa sobre la manera en la que se organiza sectorialmente la producción en el territorio, ya sea ésta concentrada en pocos sectores o más bien diversificada, lo que en sí mismo no es ni bueno ni malo. En otras palabras, para poder extraer más conclusiones es necesario recurrir a otros indicadores y a un análisis del entorno y contexto de la región y su actividad productiva.

Para presentar los resultados de una forma más sencilla, siguiendo a Soler (2000), se trabaja con la inversa del IH, que se interpreta como el número de sectores equivalentes de una economía determinada. De esta manera, la interpretación del indicador es más directa y clara: cuanto mayor 
sea la inversa del IH, más sectores equivalentes tendrá la economía y, por tanto, más diversificada será. Por el contrario, cuanto menor sea el indicador, menor será el número de sectores equivalentes, por lo que la economía estará más especializada.

Para su cálculo, el primer paso es identificar el número de sectores relevantes para la economía nacional. En Chile, el número de sectores relevantes a escala nacional asciende a 50 (n = $50)^{3}$. Considerando los 50 sectores seleccionados, se calcula el IH para el país en su conjunto, que llamaremos "IH Global" (IHG), el cual tiene valores entre $1 / \mathrm{N}(0,02)$ y 1 . Luego se procede de igual forma para calcular el IH en cada región, considerando los 50 sectores identificados para la economía nacional. Los resultados se muestran en la Tabla 6.

Como se puede observar, la región más diversificada del país es la de Los Ríos. El IH calculado para Chile da un valor de 0,047448 lo que implica 21,08 sectores equivalentes $(1 / 0,047448)$, mientras que la Región de Los Ríos presenta 25,5 sectores equivalentes. Le siguen la capital del país -Región Metropolitana-, Los Lagos y Aysén. Todas estas regiones, excepto Aysén, presentan valores por encima del promedio nacional. En otras palabras, la economía de Los Ríos podría explicarse por 26 sectores, la Región Metropolitana y Los Lagos podrían explicarse a través de 22 sectores, mientras que Aysén por 21. Estas serían las economías regionales de mayor diversificación en el contexto nacional. Por otra parte, el Maule, O’Higgins, Arica y Parinacota y Antofagasta son las regiones menos diversificadas, con una inversa del IH que se sitúa en el rango de 10 a 16 sectores equivalentes.

Estos resultados indican que, en general, las regiones de Chile se muestran como territorios diversificados. En el marco del proyecto de investigación en el que se obtuvieron estos resultados, se han estimado además estos mismos indicadores para los departamentos de Uruguay, Paraguay y El Salvador (unidades subnacionales equivalentes en términos político-administrativos a las regiones en Chile). En el caso de Uruguay, los departamentos que menos sectores equivalentes presentan muestran 6 sectores, mientras que el más diversificado (Montevideo) presenta 11 sectores equivalentes (Rodríguez Miranda et al., 2017), es decir, grados de diversificación productiva similares a los de las regiones de Chile menos diversificadas. Por su parte, los departamentos más diversificados de Paraguay (Asunción) y El Salvador (San Miguel) presentan 4 y 3 sectores equivalentes, respectivamente (Servín y Masi, 2018; Argumedo y Zuleta, 2018).

\footnotetext{
${ }^{3}$ Esta información proviene del código clasificador de actividades económicas (CIIU) en Chile. 
Tabla 6

Diversificación productiva medida por Índice de Herfindahl y su inversa 2014

\begin{tabular}{lcccc}
\hline \multicolumn{1}{c}{ Región } & IH & 1/IH & Cuartiles & $\begin{array}{c}\text { Grado de } \\
\text { diversificación }\end{array}$ \\
\hline Los Ríos & 0,039218 & 25,50 & Cuartil 4 & Alto \\
Metropolitana & 0,045127 & 22,16 & Cuartil 4 & Alto \\
Los Lagos & 0,045475 & 21,99 & Cuartil 4 & Alto \\
Aysén & 0,048831 & 20,48 & Cuartil 4 & Alto \\
Magallanes & 0,050869 & 19,66 & Cuartil 3 & Medio - Alto \\
Valparaíso & 0,053621 & 18,65 & Cuartil 3 & Medio - Alto \\
La Araucania & 0,053965 & 18,53 & Cuartil 3 & Medio - Alto \\
Tarapacá & 0,057026 & 17,54 & Cuartil 3 & Medio - Alto \\
Bío Bío & 0,057134 & 17,50 & Cuartil 2 & Medio - Bajo \\
Coquimbo & 0,060351 & 16,57 & Cuartil 2 & Medio - Bajo \\
Atacama & 0,060860 & 16,43 & Cuartil 2 & Medio - Bajo \\
Antofagasta & 0,064094 & 15,60 & Cuartil 1 & Bajo \\
Arica y Parinacota & 0,074750 & 13,38 & Cuartil 1 & Bajo \\
O'Higgins & 0,080161 & 12,47 & Cuartil 1 & Bajo \\
Maule & 0,101180 & 9,88 & Cuartil 1 & Bajo \\
\hline Promedio simple & 0,059511 & 16,80 & & \\
Chile & 0,047448 & 21,08 & & \\
\hline
\end{tabular}

Fuente: Elaboración propia.

En otros trabajos, por ejemplo, para la Comunidad Valenciana en España (Soler, 2000) se obtiene para la comarca de Valencia (alrededor de 800.000 habitantes) un indicador de 11,5 sectores equivalentes (similar a Montevideo). No obstante, aparecen otras comarcas con alto grado de especialización sectorial, en las que claramente predomina un "efecto distrito", por ejemplo, el Valle de Albaldía (90.000 habitantes) con 2,8 sectores equivalentes, el Bajo Vinalopó (280.000 habitantes) con 3,5 sectores equivalentes, el Alto Vinalopó (53.000 habitantes) con 4,1 sectores equivalentes o Alicante (455.000 habitantes) con 4,3 sectores equivalentes. En el caso de Chile, como se presentó anteriormente, las regiones menos diversificadas cuentan con 10 a 16 sectores equivalentes, por lo que se puede decir que no se registran casos de "efecto distrito" tan pronunciados.

No obstante, conviene recordar, como sugieren Rodríguez Miranda et al. (2017, p. 41), que

a priori, una alta o baja diversificación no es algo bueno o malo per se... [El IH] solo muestra el modelo de organización productiva que predomina en el territorio. Por ejemplo, una alta diversificación puede responder a la existencia de muchos sectores potentes, de actividades complejas y que tengan un alto peso en la economía nacional. Pero también una alta diversificación puede implicar la existencia de muchos sectores en el territorio, pero ninguno de ellos con un dinamismo importante ni peso destacado en la economía nacional, 
siendo más bien reflejo de una estrategia del territorio de generación de actividades de bajo dinamismo (incluso de "subsistencia") para suplir, justamente, la falta de actividades económicamente potentes.

A su vez, una economía [regional] puede presentar una alta especialización en pocos sectores y estos conformar distritos o clusters de importancia nacional que permitan sostener un entramado empresarial local potente, lo que reflejaría un desarrollo económico alto del territorio. En cambio, una alta especialización en pocos sectores también podría ser reflejo de actividades extractivas realizadas por pocas grandes empresas que no se vinculan demasiado con el entorno empresarial local, en cuyo caso el territorio seguramente presente un grado de desarrollo económico local menor que en el ejemplo anterior.

Como forma de ilustrar el grado de diversificación productiva de las regiones en Chile, se presenta a continuación el Mapa 2, el cual fue elaborado a partir de la información contenida en la Tabla 6.

\subsubsection{Especializaciones sectoriales relativas.}

A continuación, para analizar las especializaciones sectoriales relativas en cada región se utiliza el Coeficiente de Especialización (CE), el cual se calcula a partir de la siguiente fórmula:

$$
C E_{i j}=\frac{x_{i j} / x_{j}}{x_{i} / X}
$$

\section{Donde:}

- $\quad X_{i j}=$ cantidad de empresas en el sector $i$ en el territorio $j$

- $X_{J}=$ cantidad de empresas en el territorio $j$

- $\quad X_{i}=$ cantidad de empresas en el sector $i$ en el país

- $\quad X=$ cantidad de empresas en el país

Dadas las diferencias entre empresas según su tamaño (micro, pequeñas, medianas y grandes), se considera el cálculo de un CE ponderado por el tamaño de las empresas. El tamaño de las empresas está directamente relacionado con su capacidad productiva, por lo que la ponderación realizada permite ajustar mejor el indicador a la verdadera especialización de la actividad productiva de los territorios. La ponderación se realiza de acuerdo al número de trabajadores dependientes informado por parte de las empresas al Servicio de Impuestos Internos. 


\section{Mapa 2 \\ Grado de diversificación productiva por región en Chile}

2014

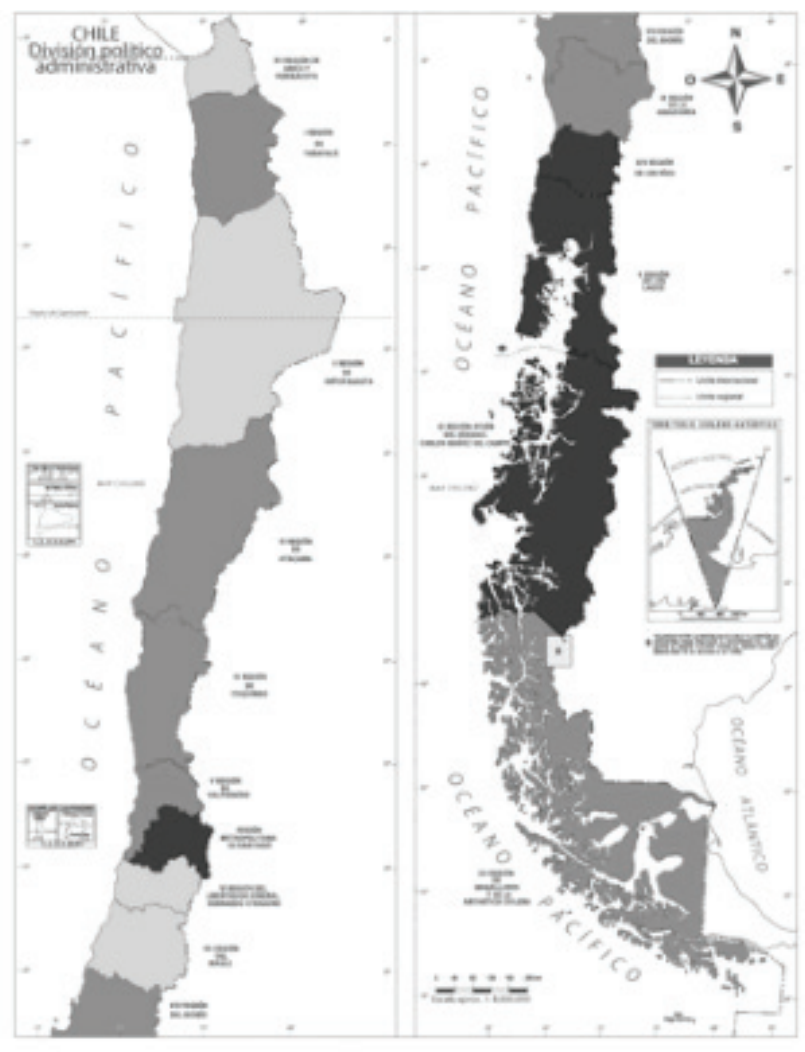

Medio Alto

Medio. Ba, o

Bajo

Fuente: Elaboración propia. Mapa del Instituto Geográfico Militar.

Los resultados del CE se interpretan de la siguiente forma: si el indicador toma valor 1, significa que el territorio tiene idéntica especialización que el promedio nacional; si $\mathrm{CE}>1$, entonces el territorio está más especializado que el promedio del país; y si $\mathrm{CE}<1$, está menos especializado. A su vez, se considera también la importancia de los sectores productivos localizados en el territorio respecto a la economía nacional a través del peso de sus empresas locales en la cantidad de empresas del sector (total nacional). Esto se analiza a través del siguiente cálculo:

$$
X_{i j} / X_{i}{ }^{\prime}=\text { participación del territorio j en el total de empresas en el sector i a escala nacional. }
$$

En la Tabla 7 se sintetiza toda la información, presentando un análisis para cada región respecto al grado de diversificación productiva, la especialización relativa sectorial y la participación absoluta 
de sus sectores en la economía nacional. Las regiones aparecen ordenadas de mayor a menor diversificación productiva, medida por el IH, lo que puede observarse en la segunda columna de la tabla.

A fin de poder analizar las especializaciones relativas sectoriales por región, en la tercera columna se considera el Coeficiente de Especialización calculado con el número de trabajadores dependientes informado. A su vez, en general, se trata de focalizar el análisis en los sectores que muestran un Coeficiente de Especialización mayor o igual que 1,5, es decir, que muestran una especialización en esa actividad productiva que es, al menos, una vez y media la que se registra a escala nacional. Lo anterior, con el objetivo de buscar centrar el estudio en aquellos sectores que realmente muestran un peso en la economía regional que es diferencial respecto al comportamiento promedio en el país, marcando una clara especialización territorial en dicho sector.

Adicionalmente, se identifica a los principales sectores de cada economía regional, de acuerdo con su peso absoluto en dicha actividad a escala nacional (última columna de la Tabla 7). Esto busca diferenciar entre las actividades que pueden mostrar especialización territorial relativa, pero tener un peso absoluto poco relevante en la economía nacional, de las actividades que además de definir una especialización relativa del territorio representan una porción significativa de dicho sector en la economía chilena.

Para focalizarse en las actividades de mayor importancia se tienen en cuenta aquellos sectores presentes en las economías regionales que representan un $4 \%$ o más de las empresas de dicho sector en el país (considerando el cálculo según número de trabajadores dependientes informado). En efecto, para el caso de Chile que tiene 15 regiones, si un sector productivo estuviera equitativamente distribuido entre las regiones, cada uno debería representar un 6,67\% de los trabajadores dependientes informados del sector. Analizando la distribución empírica de las empresas por sector y por región, siendo menos exigente que el criterio de distribución equitativa, se estimó que un 4\% era un punto de corte adecuado para considerar que los sectores tenían un peso de relevancia en el contexto nacional. 
Tabla 7

Grado de diversificación económica productiva, especializaciones sectoriales
relativas y participación sectorial en la economía nacional, según región

(tabla ordenada de mayor a menor diversificación productiva)

\begin{tabular}{|c|c|c|c|}
\hline Región & $\begin{array}{c}\text { Ranking de } \\
\text { diversificación } \\
\text { productiva (IH) }\end{array}$ & $\begin{array}{c}\text { Sectores con CE mayor o } \\
\text { igual a } 1,5\left(^{\star}\right)\end{array}$ & $\begin{array}{l}\text { Sectores con alta participación } \\
(>=4 \%) \text { a escala nacional }\end{array}$ \\
\hline Los Ríos & $\begin{array}{l}\text { Diversificación } \\
\text { relativa alta, } 1^{\circ} \mathrm{de} \\
15^{\circ} \text {, cuartil } 4\end{array}$ & $\begin{array}{l}\text { - Silvicultura y extracción de } \\
\text { madera: } 5,85 \text {. } \\
\text { - Gobierno central y } \\
\text { administración pública: } 2,41 \text {. } \\
\text { - Actividades relacionadas con } \\
\text { la salud humana: } 2,22 \text {. } \\
\text { - Actividades inmobiliarias } \\
\text { realizadas con bienes propios } \\
\text { o arrendados: } 1,65 \text {. }\end{array}$ & $\begin{array}{l}\text { La silvicultura y extracción de } \\
\text { madera destaca con el mayor aporte } \\
(9 \%) \text {. También la actividad de } \\
\text { hoteles, campamentos y otros tipos } \\
\text { de hospedaje presenta un } 4 \% \text {. }\end{array}$ \\
\hline Metropolitana & $\begin{array}{l}\text { Diversificación } \\
\text { relativa alta, } 2^{\circ} \text { de } \\
15^{\circ} \text {, cuartil } 4\end{array}$ & $\begin{array}{l}\text { - Fabricación y preparación de } \\
\text { instrumentos de óptica y } \\
\text { equipo fotográfico: } 1,57 \text {. } \\
\text { - Intermediación monctaria: } \\
1,56 \text {. } \\
\text { - Fabricación de otros } \\
\text { productos quimioco: } 1,5 \text {. } \\
\text { Es la región con mayor CE en } \\
\text { actividades económicas } \\
\text { relacionadas con el sector de } \\
\text { intermediación financiera } \\
\text { (1,46), asi como también en } \\
\text { actividades económicas } \\
\text { relacionadas con el sector de } \\
\text { actividadies inmobiliarias, } \\
\text { empresariales y de alquiler } \\
\text { (1,24). }\end{array}$ & $\begin{array}{l}\text { - Cuenta con } 23 \text { sectores que } \\
\text { aportan más del } 50 \% \text { del total } \\
\text { del rubro a escala nacional. } \\
\text { - Solo en cinco actividades } \\
\text { económicas aporta el menor } \\
\text { porcentaje del rubro a escala } \\
\text { nacional: Cultivos en general } \\
\text { (Maule); Silvicultura y } \\
\text { extracción de madera (Bio Bio); } \\
\text { Explotación de criaderos de } \\
\text { peces y productos del mar (Los } \\
\text { Lagos); Pesca extractiva (Bio } \\
\text { Bio) y Extracción de minerales } \\
\text { metaliferos (Coquimbo). } \\
\text { El mayor aporte a nivel pais lo } \\
\text { realiza en las actividades } \\
\text { relacionadas con el sector de } \\
\text { intermediación financiera con } \\
\text { un } 83 \% \text {. }\end{array}$ \\
\hline Los Lagos & $\begin{array}{l}\text { Diversificación } \\
\text { relativa alta, } 3^{\circ} \text { de } \\
15^{\circ} \text {, cuartil } 4\end{array}$ & $\begin{array}{l}\text { - Explotación de criaderos de } \\
\text { poces y productos del mar: } \\
20,03 \text {. } \\
\text { - Actividades deportivas y } \\
\text { otras actividades de } \\
\text { esparcimiento: } 3,10 \text {. } \\
\text { Producción, procesamiento y } \\
\text { conservación de alimentos: } \\
2,68 \text {. } \\
\text { Pesca extractiva: } 2,31 \text {. }\end{array}$ & $\begin{array}{l}\text { - Explotación de criaderos de } \\
\text { peces y productos del mar con } \\
\text { un } 65 \% \text {. } \\
\text { - Pesca extractiva con un } 16 \% \text {. } \\
\text { - Hoteles, campamentos y otros } \\
\text { tipos de hospedaje temporal con } \\
\text { un } 12 \% \text {. } \\
\text { Producción, procesamiento y } \\
\text { conservación de alimentos con } \\
\text { un } 11 \% \text {. } \\
\text { Oxras nueve actividades } \\
\text { económicas aportan al pais entre } \\
\text { un } 4 \% \text { y } 6 \%\end{array}$ \\
\hline Aysén & $\begin{array}{l}\text { Diversificación } \\
\text { relativa alta, } 4^{\circ} \text { de } \\
15^{\circ} \text {, cuartil } 4\end{array}$ & $\begin{array}{l}\text { - Pesca extractiva: } 48,49 \text {. } \\
\text { - Explotación de criaderos de } \\
\text { peces y productos del mar: } \\
12,67 \text {. } \\
\text { - Extracción de minerales } \\
\text { metaliferos } 4,66 \text {. } \\
\text { - Captación, depuración y } \\
\text { distribución de agua: } 4,3 \text {. } \\
\text { - Fabricación de gas, } \\
\text { distribución de combustibles } \\
\text { gascosos por tuberias: } 4,15 \text {. }\end{array}$ & $\begin{array}{l}\text { - Explotación de criaderos de } \\
\text { poces y productos del mar con } \\
\text { un } 6 \% \text {. } \\
\text { - Hoteles, campamentos y otros } \\
\text { tipos de hospedaje temporal oxn } \\
\text { un } 4 \% \text {. } \\
\text { - En las demás actividades } \\
\text { económicas, su contribución es } \\
\text { menor o igual al } 2 \% \text {. }\end{array}$ \\
\hline
\end{tabular}




\begin{tabular}{|c|c|c|c|}
\hline & & $\begin{array}{l}\text { - Gobierno central y } \\
\text { - Edministración püblica: } 1,95 \text {. } \\
\text { Explotación de miras y } \\
\text { carteras: } 1,86 \text {. } \\
\text { - Hoteles, campamentos y } \\
\text { otros tipos de bospedaje } \\
\text { temporal: } 1,63 \text {. }\end{array}$ & \\
\hline Magallanes & $\begin{array}{l}\text { Diversificación } \\
\text { relativa media-alta, } \\
5^{\circ} \text { de } 15^{\circ} \text {, cuartil } 3\end{array}$ & $\begin{array}{l}\text { - Pesca extractiva: } 12,52 \text {. } \\
\text { - Explotación de criaderos de } \\
\text { peces y productos del mar. } \\
4,97 \\
\text { - Explotación de miras y } \\
\text { carteras: } 4,66 \text {. } \\
\text { Hoteles, campamentos y } \\
\text { otros tipos de bospedaje } \\
\text { temporal: } 3,88 \text {. } \\
\text { - Producción, procesamiento y } \\
\text { conservación de alimentos: } \\
3,18 \text { de vehiculos } \\
\text { Venta de } \\
\text { automotores: } 2,03 \text {. } \\
\text { Venta al por mayoe de } \\
\text { materias primas } \\
\text { agropecuarias: } 1,89 \text {. } \\
\text { Actividades relacionadas con } \\
\text { la salud humana: } 1,71 \text {. } \\
\text { Comercio al poe menor de } \\
\text { otros productos ruevos: } 1,53 \text {. }\end{array}$ & $\begin{array}{l}\text { - Pesca extractiva con un } 21 \% \\
\text { - Organizaciones y óngaros } \\
\text { territociales con un } 7 \% \\
\text { - En las demás actividades } \\
\text { económicas, su contribución es } \\
\text { menoe o igual al } 3 \%\end{array}$ \\
\hline Valparaiso & $\begin{array}{l}\text { Diversificación } \\
\text { relativa media-alta, } \\
6^{\circ} \text { de } 15^{\circ} \text {, cuartil } 3\end{array}$ & 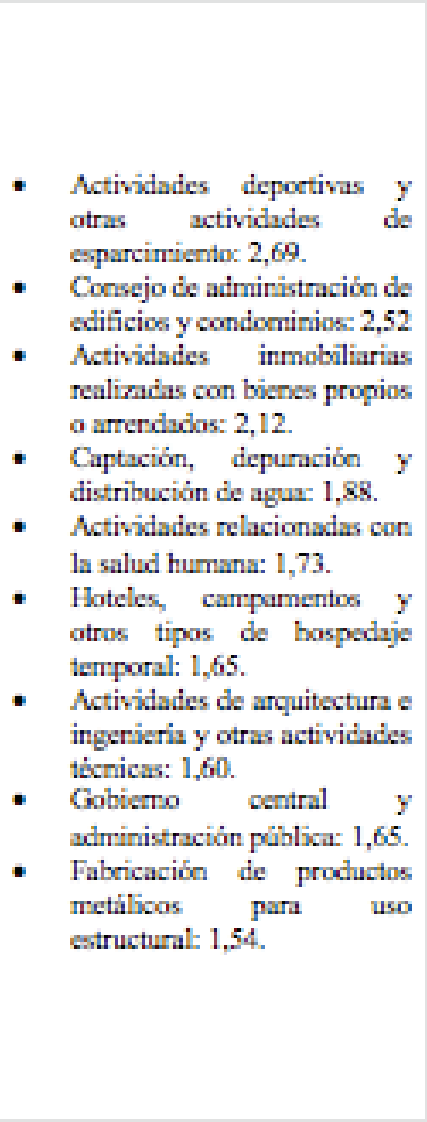 & 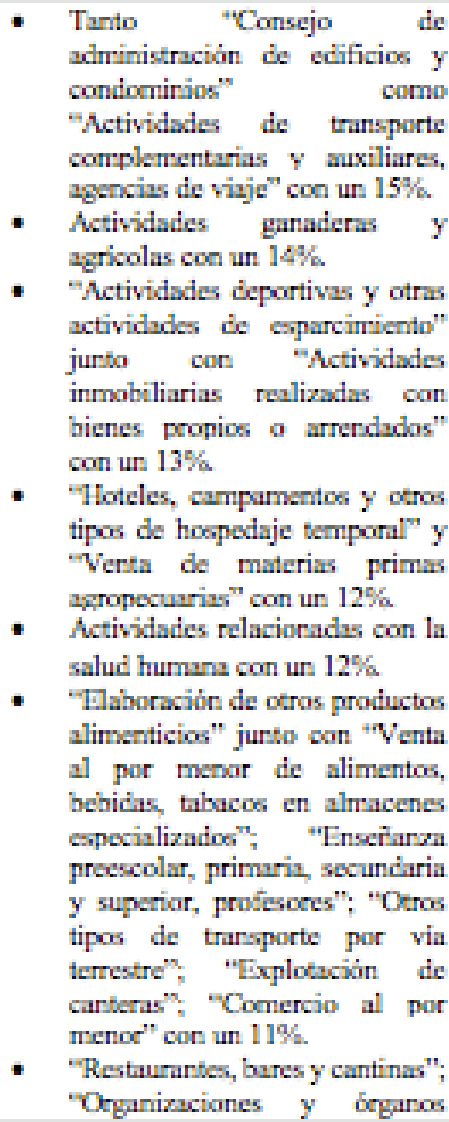 \\
\hline
\end{tabular}




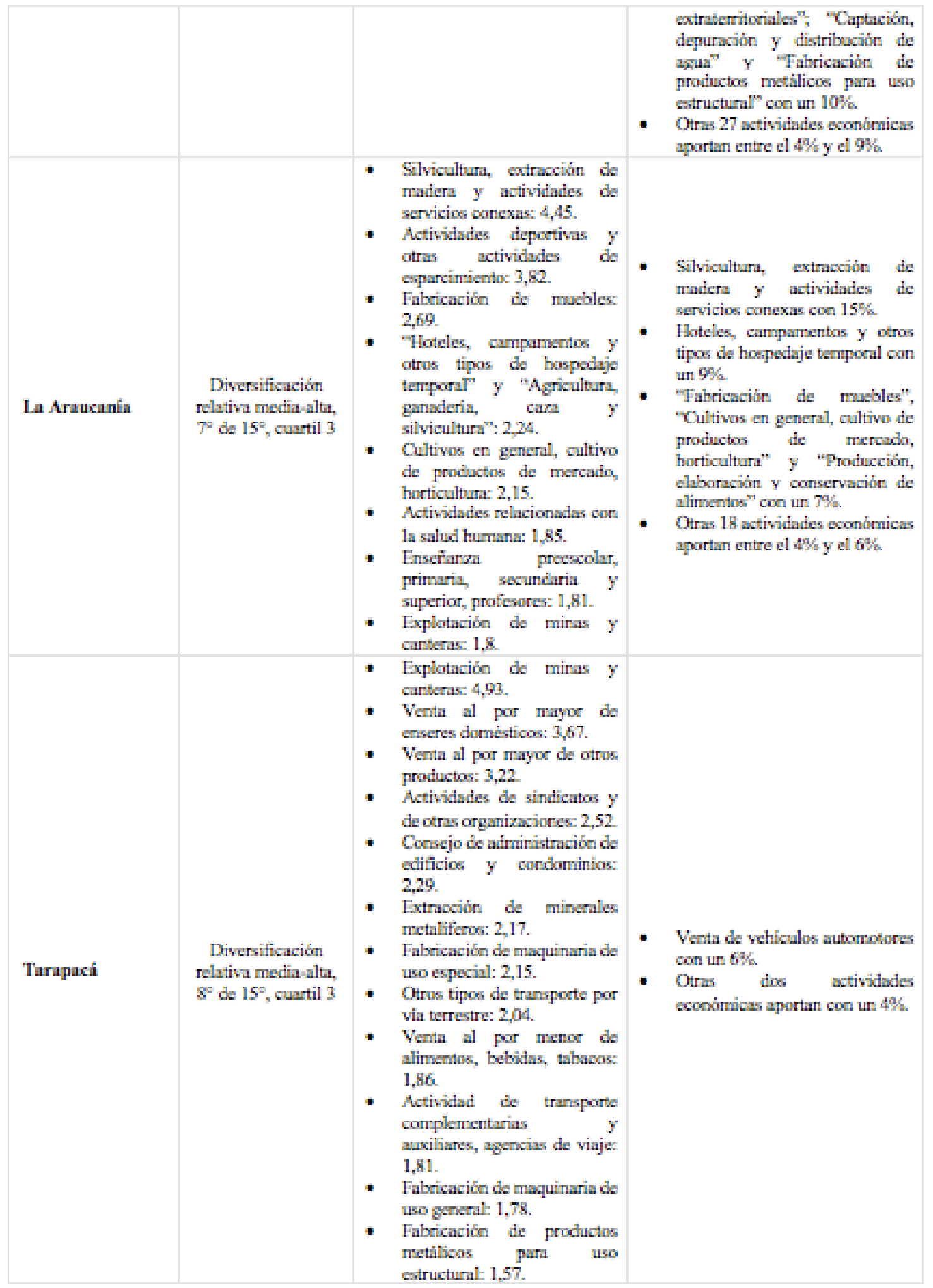




\begin{tabular}{|c|c|c|c|}
\hline & & $\begin{array}{l}\text { - Enscianza precscolar, } \\
\text { primariz, secundaria y } \\
\text { superior, profesores: } 1,55 \text {. } \\
\text { Actividades relacionadas con } \\
\text { la salod humanz: } 1,51 \text {. }\end{array}$ & \\
\hline Bío Bío & $\begin{array}{l}\text { Diversificación } \\
\text { relativa media baja, } \\
9^{\circ} \text { de } 15^{\circ} \text {, cuartil } 2\end{array}$ & $\begin{array}{l}\text { - Silvicultara y extracción de } \\
\text { madera: } 6,05 \text {. } \\
\text { - Pesca extractiva } 65,23 \text {. } \\
\text { - Fabricación de productos } \\
\text { Metilicos para uso } \\
\text { estructural: 2,81. } \\
\text { Captación, depuración y } \\
\text { distribución de agua: } 2,75 \text {. } \\
\text { Enscianza preescolar, } \\
\text { primariz, secundaria y } \\
\text { superior, profesores y } \\
\text { Actividades deportivas y } \\
\text { otras actividades de } \\
\text { esparcimiento: } 1,63 \text {. }\end{array}$ & $\begin{array}{l}\text { - Silvicultara y extracción de } \\
\text { madera con un } 31 \% \text {. } \\
\text { - Pesca extractiva con un } 22 \% \text {. } \\
\text { - Fabricación de gas, distribución } \\
\text { de combustibles gascosos por } \\
\text { taberias con un } 19 \% \text {. } \\
\text { - Fabricación de productos } \\
\text { metilicos para uso estructural } \\
\text { con un } 16 \% \text {. } \\
\text { Captación, depuración y } \\
\text { distribución de agua con un } \\
18 \% \text {. Comercio al por menor no } \\
\text { " especializado en almacenes", } \\
\text { "Fabricación de maquinaria de } \\
\text { uso general", junto con "Venta } \\
\text { al por menor de alimentos, } \\
\text { bebidas, tabacos en almacenes } \\
\text { especializados" con un } 12 \% \text {. }\end{array}$ \\
\hline Coquimbo & $\begin{array}{c}\text { Diversificación } \\
\text { relativa media baja, } \\
10^{2} \text { de } 15^{\circ} \text {, cusrtil } 2\end{array}$ & 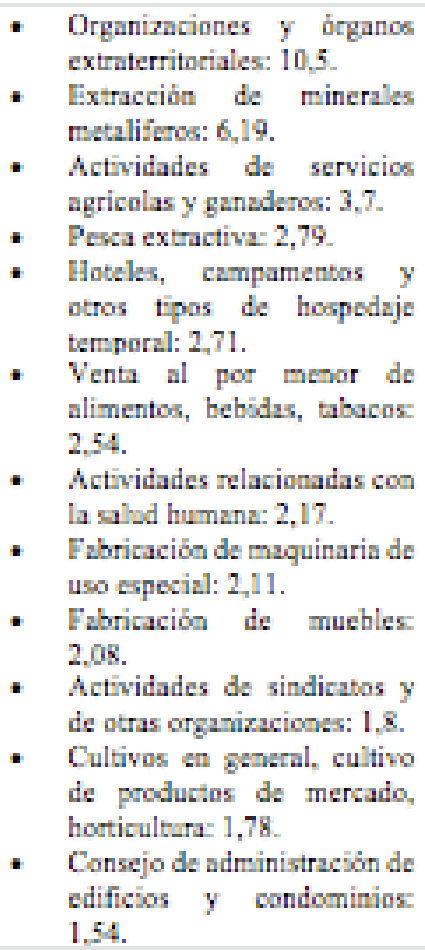 & 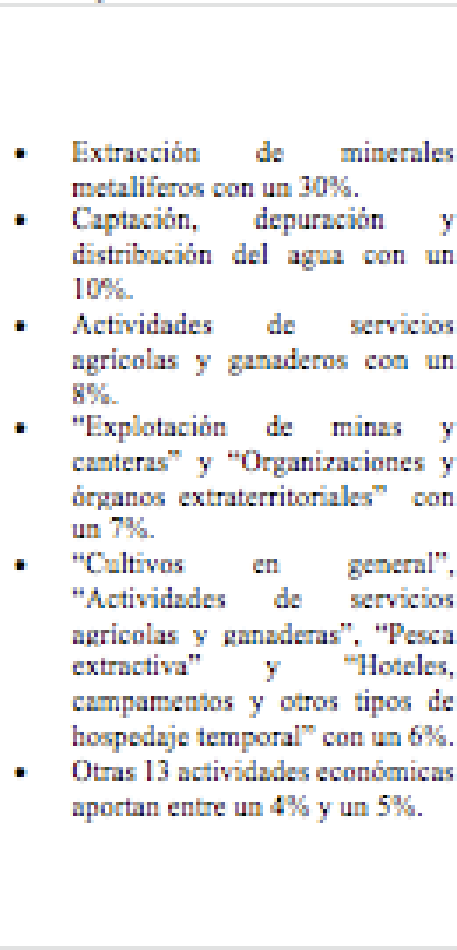 \\
\hline Atacama & $\begin{array}{l}\text { Diversificación } \\
\text { relativa media baja, } \\
11^{a} \text { de } 15^{\circ} \text {, cuartil } 2\end{array}$ & $\begin{array}{l}\text { - Extracción de minerales } \\
\text { metaliferos: 13,55. } \\
\text { - Fabricación de productos } \\
\text { metilicos para uso } \\
\text { estructural: 3,65. } \\
\text { Explotación de minas y } \\
\text { carteras: 3,43. } \\
\text { Captación, depuración y } \\
\text { distribución de agua: } 3,03 \text {. }\end{array}$ & $\begin{array}{l}\text { - Extracción de minerales } \\
\text { metaliferos con un } 30 \% \text {. } \\
\text { "Hoteles, campamentos y otros } \\
\text { tipos de hospodaje temporal" y } \\
\text { "Captación, depurzción y } \\
\text { distribución de agua" con un } \\
4 \% \text {. }\end{array}$ \\
\hline
\end{tabular}




\begin{tabular}{|c|c|c|c|}
\hline & & $\begin{array}{l}\text { - Hoteles, czmpamentos y } \\
\text { atros tipos de hospedzje } \\
\text { temporzl: } 2,84 \text {. } \\
\text { - Gobierno entral y } \\
\text { administración públicz: } 2,50 \text {. } \\
\text { - Fabricación de maquinaria de } \\
\text { uso especial: } 2,29 \text {. } \\
\text { - Actividades de servicios } \\
\text { agricolas y ganaderos: } 2,25 \text {. }\end{array}$ & $\begin{array}{l}\text { - Las demis actividzdes aportan } \\
\text { en una cantidad menor o iguzl al } \\
3 \% \text {. }\end{array}$ \\
\hline Antofagasta & $\begin{array}{l}\text { Diversificación } \\
\text { relativa bzjz, } 12^{\circ} \mathrm{de} \\
15^{\circ} \text {, cuartil } 1\end{array}$ & $\begin{array}{l}\text { - Extracción de minerales } \\
\text { metaliferos: } 6,4 \text {. } \\
\text { Captación, depuración y } \\
\text { distribución de agua: } 5,01 \text {. } \\
\text { - Fabricación de maquinaria de } \\
\text { uso general: } 3,82 \text {. } \\
\text { - Fabricación de otros } \\
\text { prodactos. elaborados de } \\
\text { metal: } 3,50 \text {. } \\
\text { Fabricación de productos } \\
\text { metílicos para uso } \\
\text { estructural: } 3,35 \text {. } \\
\text { Explotación de minzs y } \\
\text { czanteras: } 2,72 \text {. } \\
\text { Fabricación de maquinaria de } \\
\text { uso especial: } 2,55 \text {. } \\
\text { Hoteles, czmpamentos y } \\
\text { otros tipos de hospedzje } \\
\text { temporzl: } 2,51 \text {. } \\
\text { Actividades deportivas y } \\
\text { otras actividades de } \\
\text { esparcimiento: } 2,06 \text {. } \\
\text { Venta al por menor de } \\
\text { alimentos, bebidas, tabacos: } \\
1,97 \text {. } \\
\text { Otros tipos de transporte por } \\
\text { via tertestre: } 1,63 \text {. } \\
\text { Constrocción: } 1,55 \text {. }\end{array}$ & $\begin{array}{l}\text { - Extracción de minerales } \\
\text { metaliferos con un } 10 \% \text {. } \\
\text { - Hoteles, campamentos y otros } \\
\text { tipos de hospedaje temporal con } \\
\text { un } 6 \% \text {. } \\
\text { - Explotación de minzs y canteras } \\
\text { con un } 5 \% \text {. } \\
\text { Fabricación de maquinaria de } \\
\text { uso general y de uso especial con } \\
\text { un } 5 \% \text { y } 4 \% \text {, respectivamente. } \\
\text { "Restaurantes, bares y cantinas" } \\
\text { y "Constrocción" con un } 4 \% \text {. } \\
\text { Otras } 6 \text { actividades económicas } \\
\text { aportan un } 4 \% \text {. }\end{array}$ \\
\hline Ariea y Parinacota & $\begin{array}{l}\text { Diversificación } \\
\text { relativa bzjz, } 13^{\circ} \mathrm{de} \\
15^{\circ} \text {, cuartil 1 }\end{array}$ & 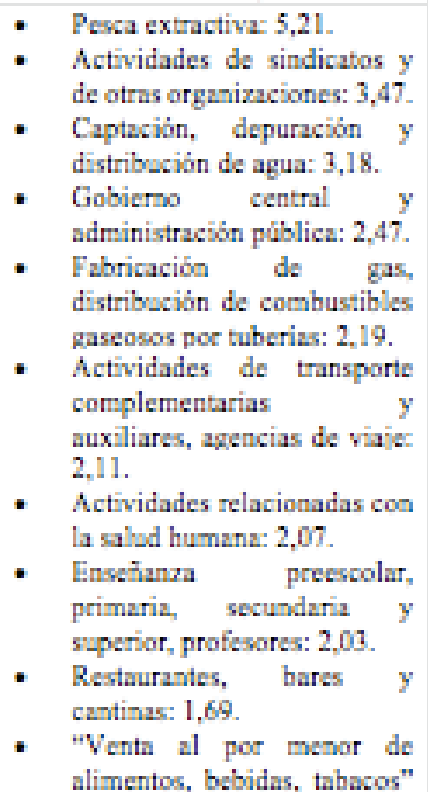 & $\begin{array}{l}\text { Destacan "Organizaciones y órganos } \\
\text { extraterritoriales", junto con "Venta } \\
\text { al por menor de alimentos, bebidzs, } \\
\text { tabacos en almacenes especializzdos" } \\
\text { con un } 3 \% \text {. } \\
\text { E resto de las actividades } \\
\text { económicas aporta ea menor } \\
\text { porcentaje. }\end{array}$ \\
\hline
\end{tabular}




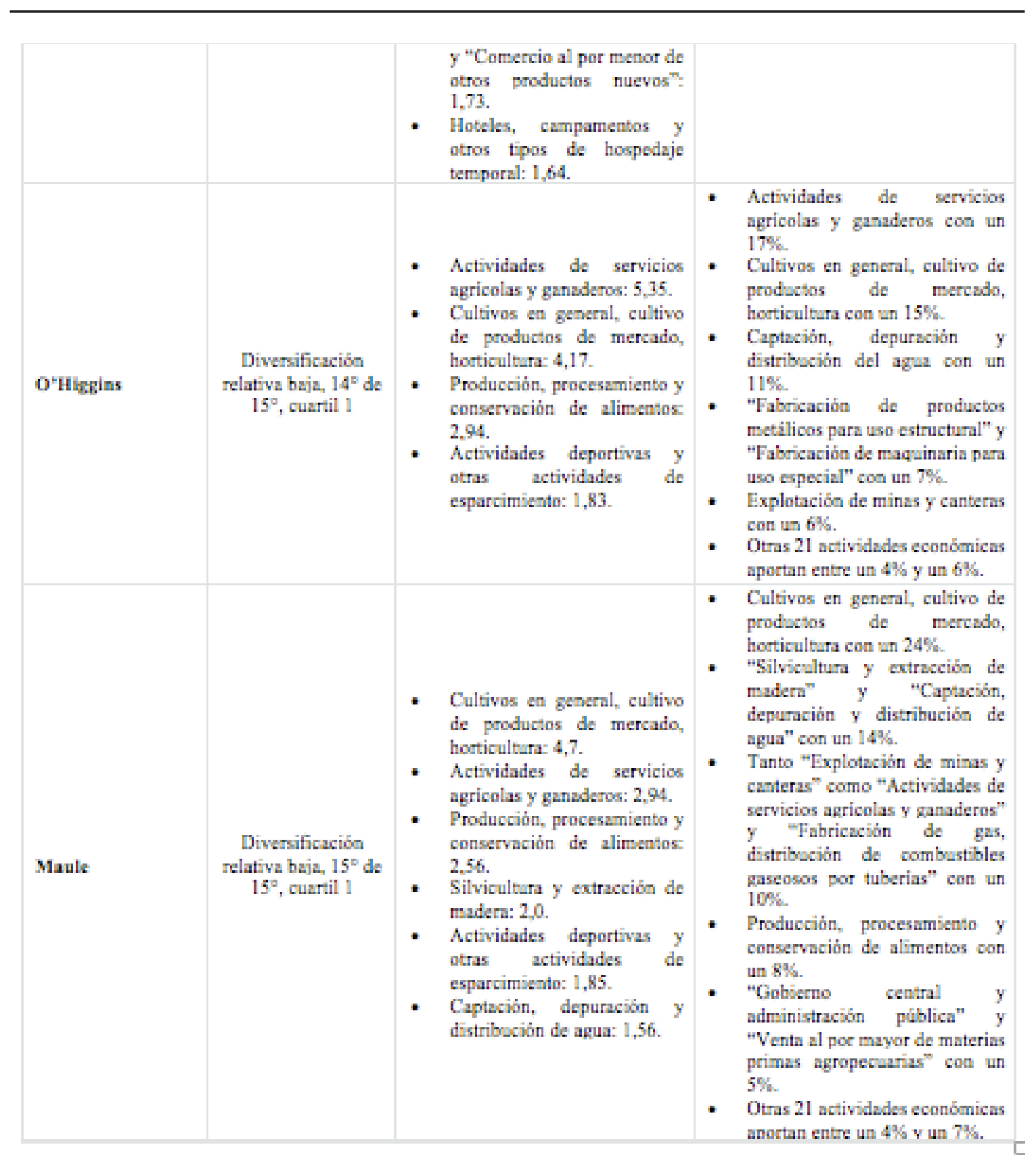

Nota (*): No se consideran los sectores bajo la denominación "Otros" porque son residuales.

Fuente: Elaboración propia. 


\subsection{Análisis por regiones.}

\subsubsection{Región Metropolitana y Valparaíso.}

Mapa 3

\section{Región Metropolitana y Valparaíso}

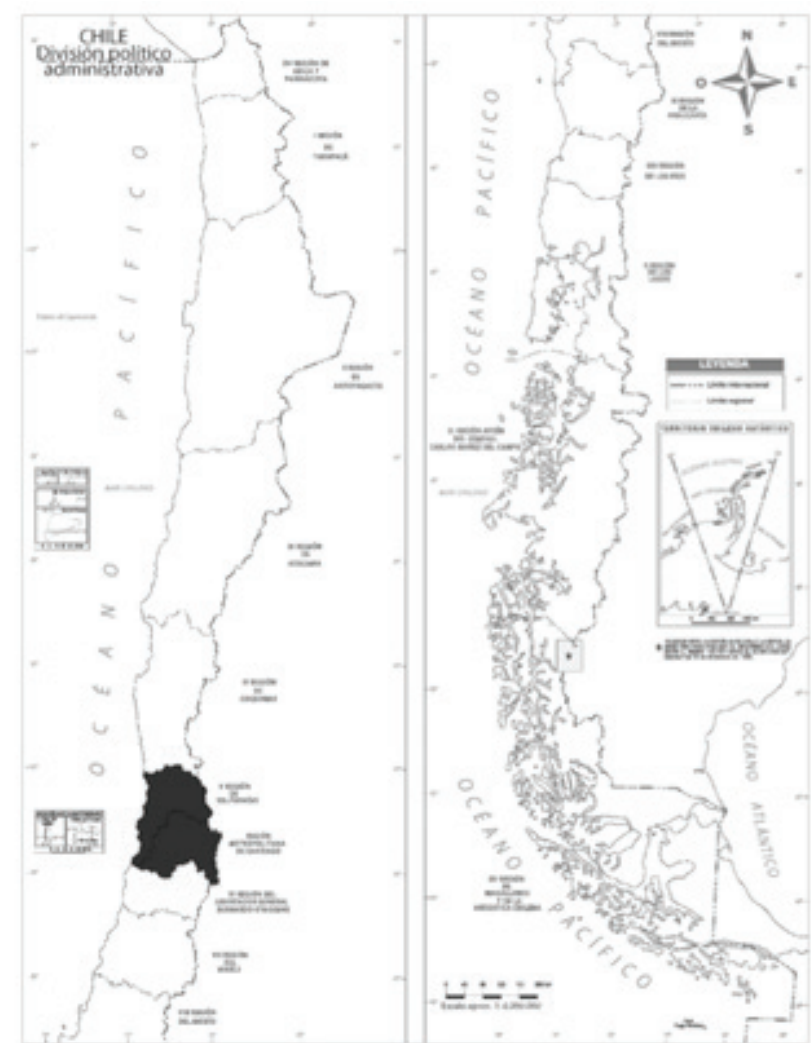

Estas regiones albergan a la capital -Santiago- y al principal puerto del país. En la Región Metropolitana y en Valparaíso se observa una lógica metropolitana con el desarrollo de actividades más complejas que en el resto del país, orientadas en mayor grado al sector servicios. Se trata de economías que muestran, como es de esperar en ciudades grandes, una fuerte diversificación productiva, y con sectores que, además, tienen un peso importante a escala nacional.

En efecto, la Región Metropolitana cuenta con 23 sectores que aportan más del 50\% del total del rubro a nivel país. En este sentido, destaca que un $83 \%$ de las actividades relacionadas con el sector de intermediación financiera se producen en esta región.

Por su parte, la Región de Valparaíso destaca en actividades de transporte, como consecuencia fundamentalmente de la actividad portuaria. Además, sus ciudades y localidades costeras atraen a muchos turistas nacionales y extranjeros, por su proximidad a Santiago y su buena conec- 
tividad, lo que se ve reflejado en la importancia del sector de hoteles, campamentos y otros tipos de hospedaje temporal, así como en el de agencias de viaje. También, sobresalen las actividades inmobiliarias realizadas con bienes propios o arrendados.

\subsubsection{Región de Los Lagos.}

Mapa 4

\section{Región de Los Lagos}

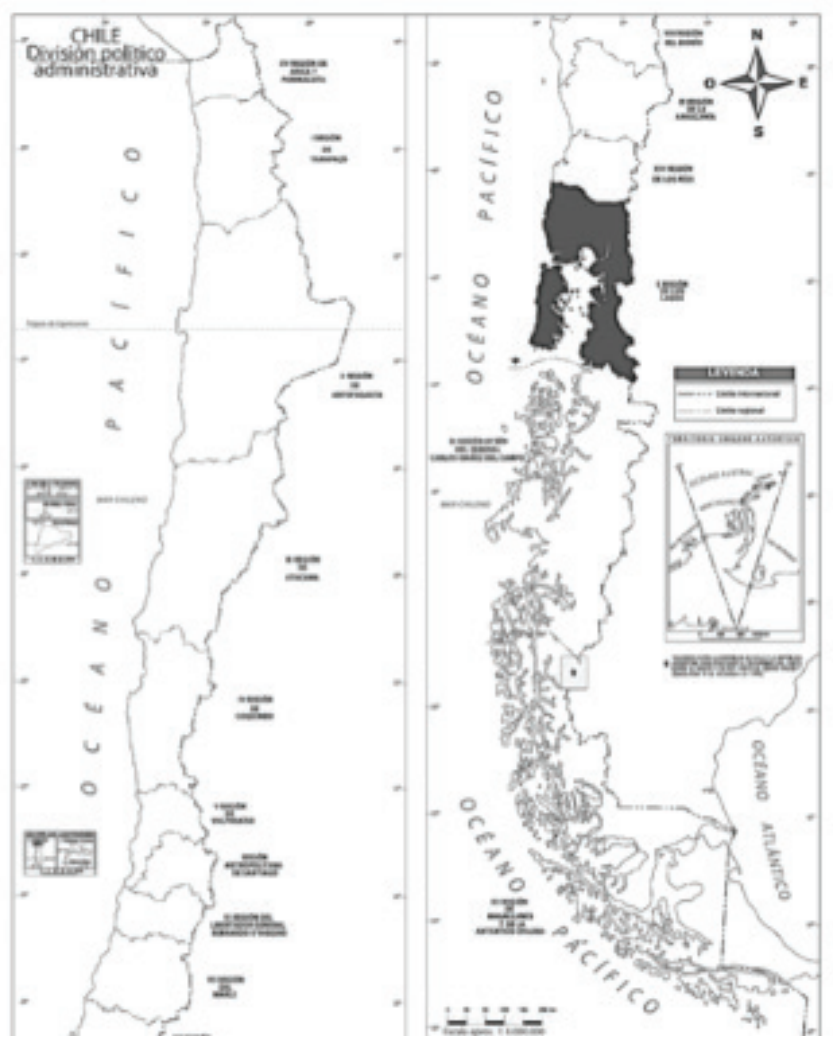

La Región de Los Lagos tiene una diversificación relativa alta. Muestra un perfil productivo que incluye actividades de base primaria, pero también hay cierta presencia de actividad industrial y de servicios. La región es conocida por la industria del salmón, por lo que no es extraño que cuente con la mayor participación a escala nacional en explotación de criaderos de peces y productos del mar, con un $65 \%$. Dentro del sector industrial, se encuentra la presencia de sectores de actividad como producción, procesamiento y conservación de alimentos. A su vez, el turismo es una actividad importante, lo que se refleja en la especialización en actividades deportivas y otras actividades de esparcimiento, así como la alta participación en hoteles y restaurantes. 


\subsubsection{Zona Austral.}

Mapa 5

\section{Zona Austral}

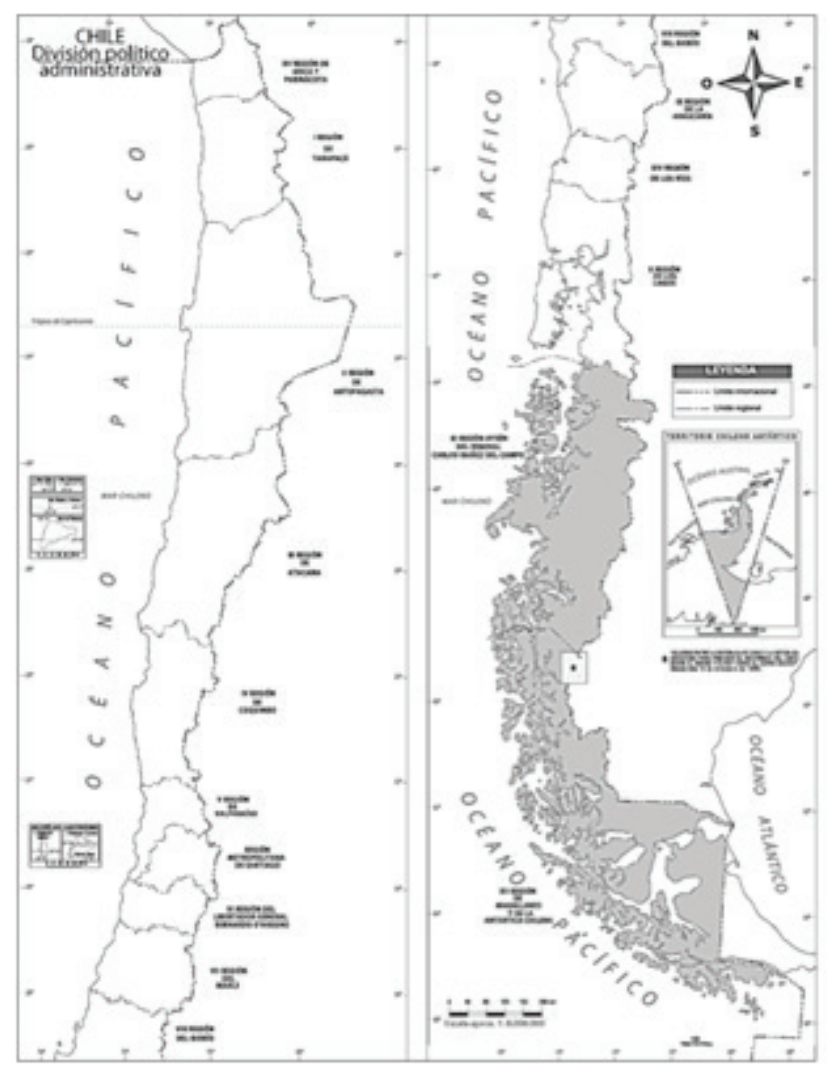

Las regiones que conforman la zona austral del país -Aysén y Magallanes- se encuentran entre las más diversificadas del país, con 21 y 20 sectores equivalentes, respectivamente.

Como es natural, dadas sus similitudes geográficas, ambas regiones muestran un perfil productivo muy parecido basado en actividades económicas primarias: pesca extractiva, explotación de criaderos de peces y productos del mar, y servicios relacionados con la industria. En ambas regiones existe una fuerte especialización en actividades primarias, en específico, en el sector pesquero. 
3.3.4. Bío Bío y Los Ríos.

Mapa 6

Bío Bío y Los Ríos

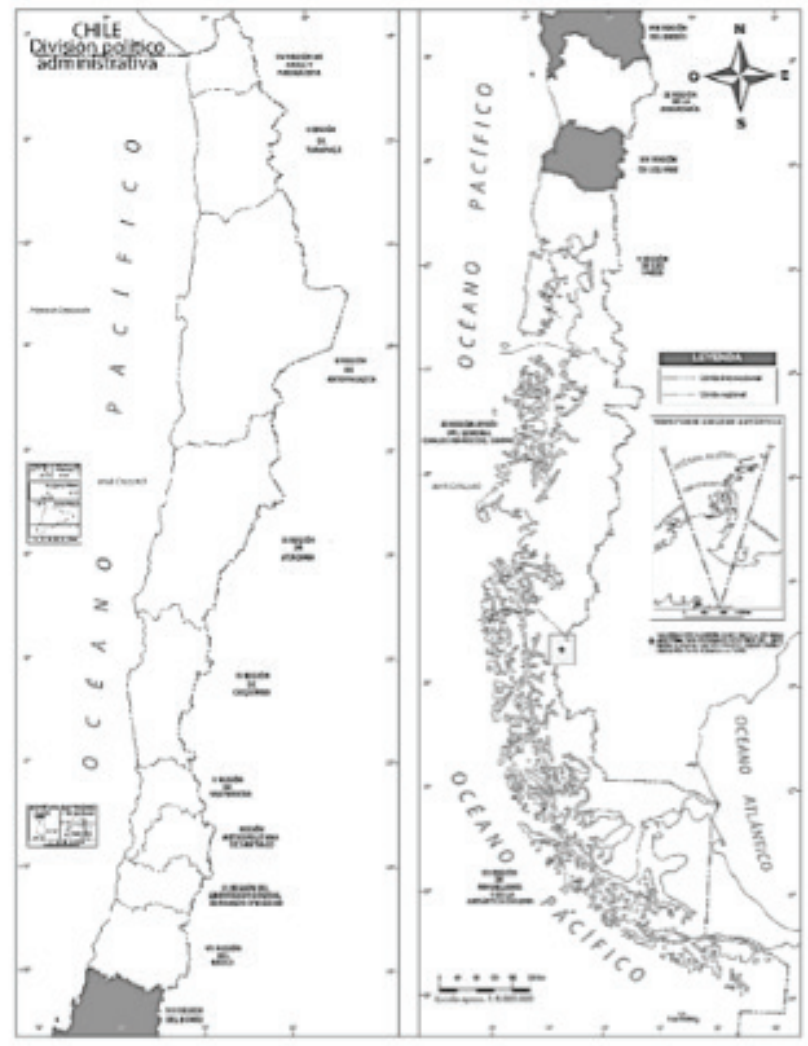

El Bío Bío y Los Ríos son regiones de la zona sur del país, que muestran economías especializadas en la producción primaria con un menor desarrollo de los sectores industriales y de servicios, más allá de algunas agroindustrias y empresas forestales importantes. Ambas regiones muestran una especialización en la silvicultura y extracción de madera.

Como ya se indicó anteriormente, Los Ríos es la región más diversificada de Chile, con 26 sectores equivalentes (ver Tabla 6). No obstante, su producción está principalmente orientada a la ganadería bovina, la agricultura, la explotación maderera y el procesamiento de celulosa. Además, el turismo es una importante fuente de desarrollo para la región, no sólo en la capital -Valdivia-, sino que también en la zona interior lacustre (Llisterri y Pietrobelli, 2011).

Por su parte, Bío Bío tiene una diversificación relativa media-baja (puesto $9^{\circ}$ de 15 regiones). En ella, conviven una importante área metropolitana alrededor de la ciudad de Concepción, con cierta diversificación productiva, junto a grandes bosques y una marcada especialización en la silvicultura y extracción de madera, actividad en la que la región representa la mayor participación a escala nacional $(31 \%)$. 


\subsubsection{Región de La Araucanía.}

Mapa 7

La Araucanía

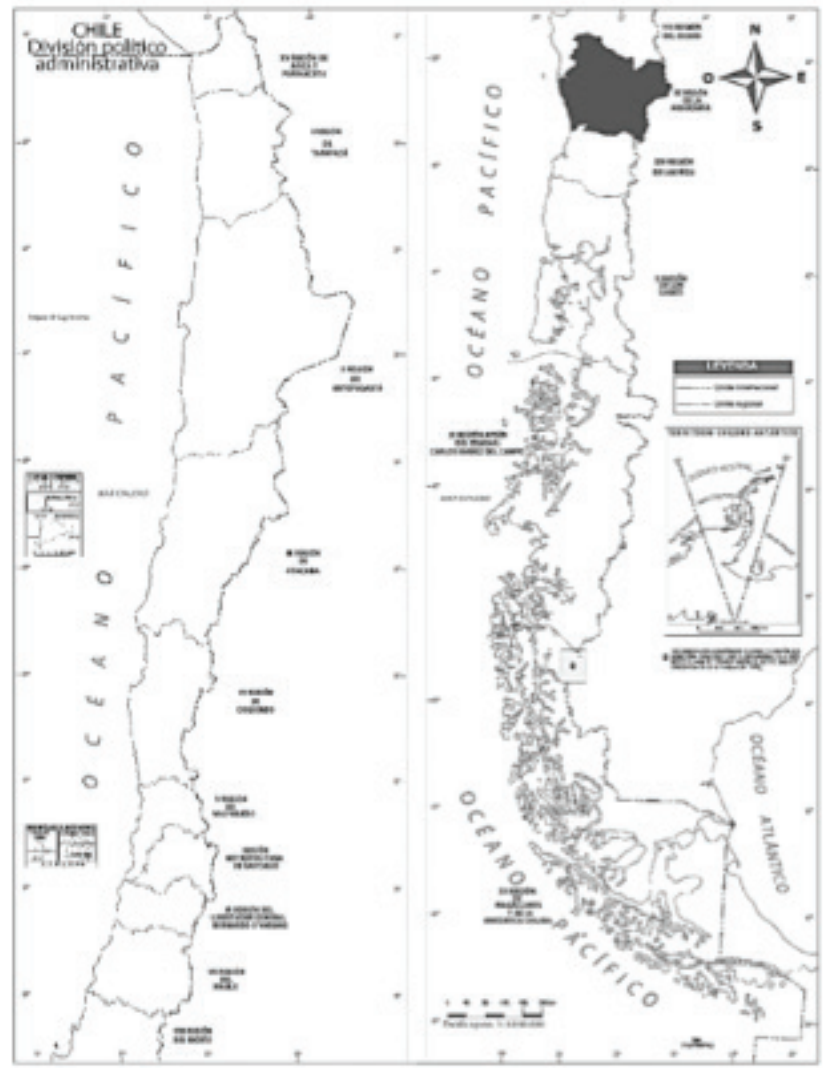

Como se mencionó anteriormente, las regiones ubicadas en la zona sur del país muestran economías más especializadas en la producción primaria y con un menor desarrollo de los sectores industriales y de servicios. La Araucanía presenta una diversificación productiva media alta en la que destacan los sectores de silvicultura, extracción de madera y actividades de servicios conexas y, por ende, también sobresale la actividad de fabricación de muebles.

Además, en la región hay un fuerte desarrollo de los servicios vinculados a actividades relacionadas con el turismo. En este sentido, cabe señalar que La Araucanía cuenta con varios atractivos turísticos que son visitados por personas de la región, del país y del extranjero. En consecuencia, destacan los sectores de hoteles, campamentos y otros tipos de hospedaje temporal, restaurantes, operadores turísticos, deportes y recreación.

No obstante, también hay especialización en otras actividades de base primaria, como lo son la agricultura, ganadería, caza y silvicultura, cultivos en general, cultivo de productos de mercado y horticultura. En cuanto a la agricultura, destacan los cultivos tradicionales de cereales como el trigo, la avena, la cebada y el raps, además de la papa y el lupino. Por su parte, la ganadería se 
benefició de una transformación en el uso de la tierra en las últimas décadas, permitiendo el desarrollo de una importante masa ganadera -bovina, porcina, ovina y equina-, en la que destaca la producción de leche y sus derivados (Llisterri y Pietrobelli, 2011).

\subsubsection{Región Zona Norte.}

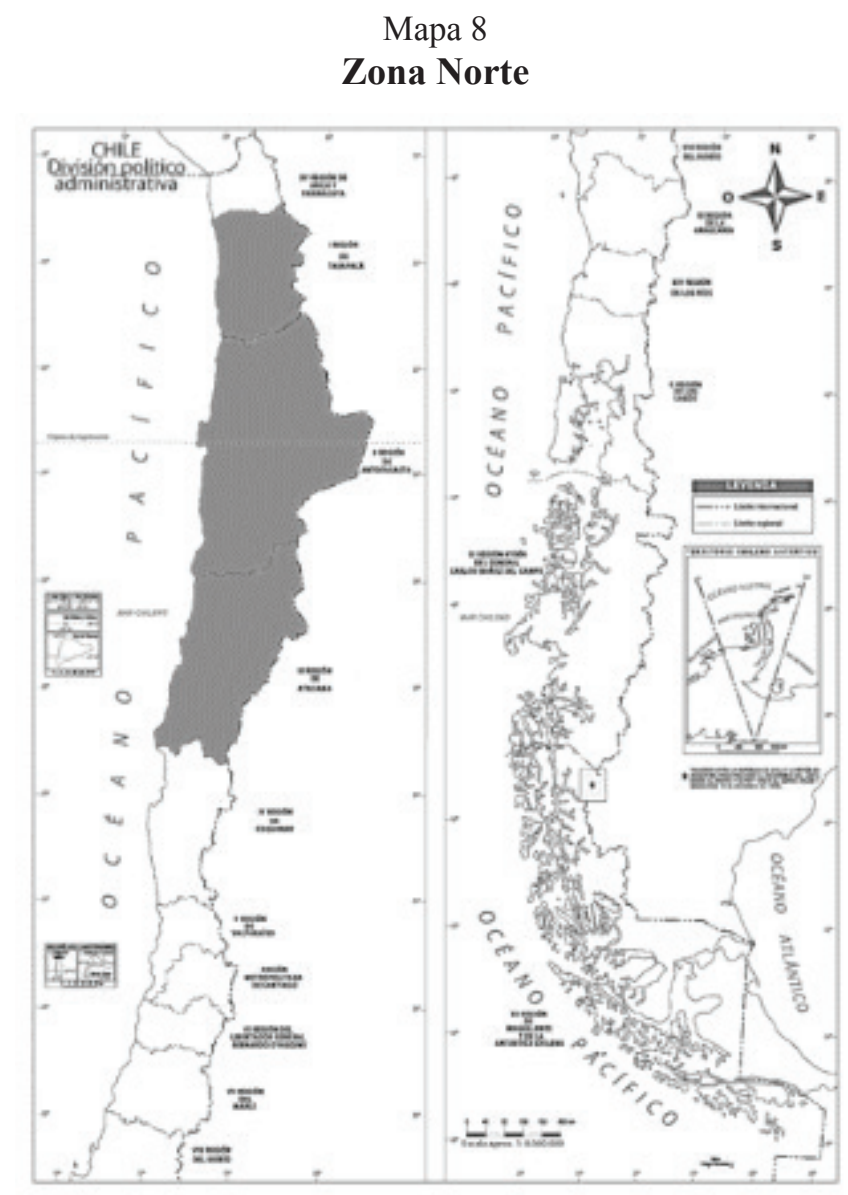

Las regiones del norte -Tarapacá, Antofagasta y Atacama- se caracterizan por ser las regiones en las que se localiza mayoritariamente la producción minero extractiva del país. Además, la minería tiene un efecto de arrastre sobre la construcción y la energía, elementos fundamentales para el desarrollo productivo de las faenas extractivas (Frigolett, 2013).

No obstante, estas regiones se encuentran entre las regiones menos diversificadas de Chile y muestran un perfil productivo similar de base primaria e industrial. En ellas, destaca la explotación de minas y canteras y la extracción de minerales metalíferos. Antofagasta y Atacama cuentan, además, con el desarrollo de la industria del metal. 


\subsubsection{Región de Coquimbo.}

\section{Mapa 9}

\section{Coquimbo}

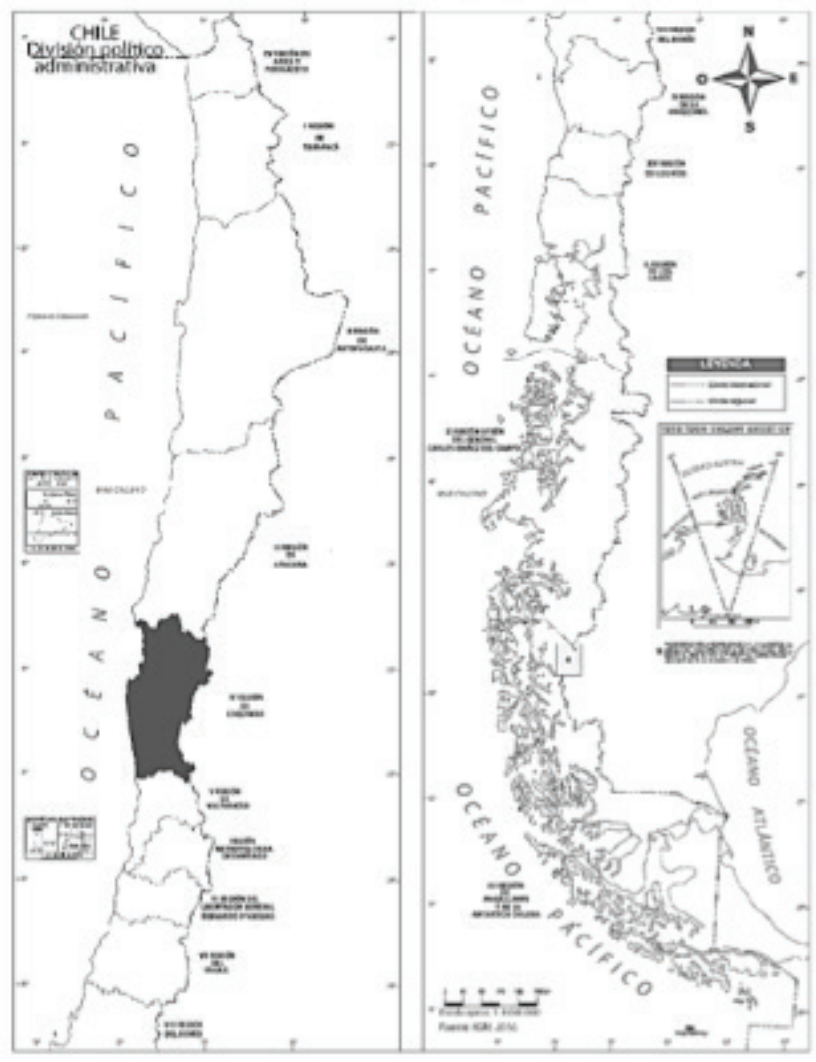

La Región de Coquimbo se caracteriza por una diversificación relativa media-baja y por mostrar un perfil productivo que incluye el desarrollo de actividades primarias, pero también la presencia de servicios. Dentro de las primeras, destacan la extracción de minerales metalíferos, actividades de servicios agrícolas y ganaderos, explotación de minas y canteras y pesca extractiva. En el caso de los servicios, se encuentran presentes las actividades relacionadas con organizaciones y órganos extraterritoriales, y al ser una región turística, también destaca la actividad de hoteles, campamentos y otros tipos de hospedaje temporal. 
3.5.8. Región Frontera Norte.

Mapa 10

Frontera Norte

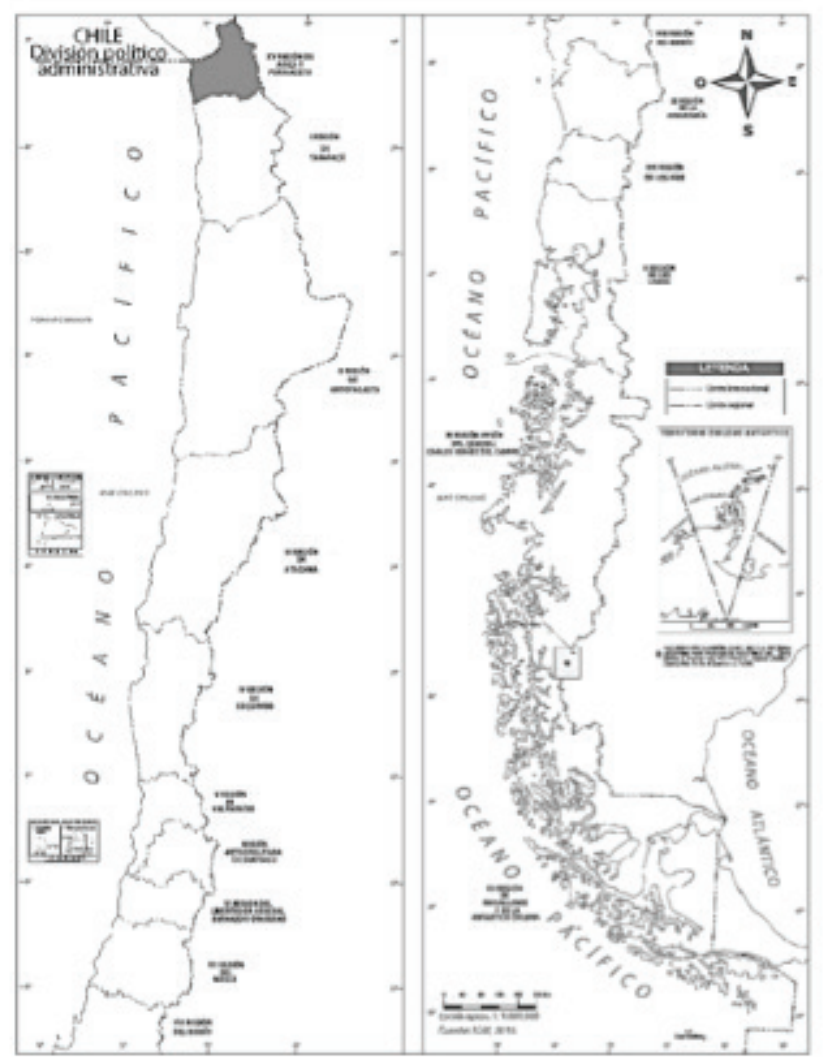

La Región de Arica y Parinacota se sitúa en el límite fronterizo con Perú y Bolivia al norte del país. Es una de las regiones que presenta menor diversificación a escala nacional (puesto 13 de 15). Como pequeña economía regional, destaca únicamente en organizaciones y órganos extraterritoriales con un 3\%, es decir, que su especialización se produce en aquellos sectores relacionados con instituciones públicas -gobierno central y administración pública-. También, actividades relacionadas con la salud humana, servicios y comercio. El resto de las actividades económicas aporta en menor porcentaje. 


\subsubsection{Zona Central.}

Mapa 11

\section{Zona Central}

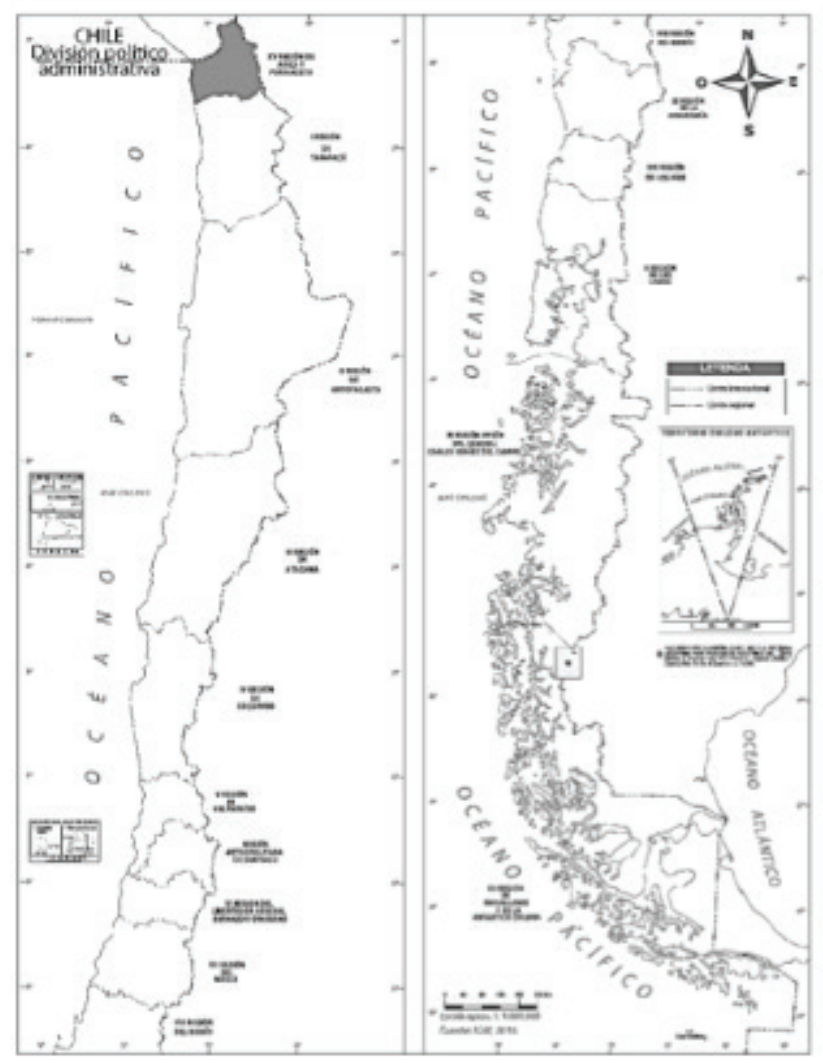

Las regiones de O'Higgins y del Maule, ubicadas en la zona central del país, son las regiones con una mayor concentración o menor diversificación productiva relativa en Chile. En ellas predominan los valles de clima templado, lo que ha favorecido una especialización productiva que se concentra en el desarrollo agrícola y frutícola, así como en la industrialización de la producción agropecuaria primaria. En ambas regiones, por tanto, destacan las actividades de base primaria y agroindustrial, esto es: actividades de servicios agrícolas y ganaderos, cultivos en general, cultivo de productos de mercado y horticultura y, finalmente, producción, procesamiento y conservación de alimentos. Además, en el Maule, dada su cercanía con la Región del Bío Bío, principal plataforma de plantaciones forestales en el país, se presenta la actividad de silvicultura y extracción de madera.

En O’Higgins y Maule, además de las actividades del sector primario, se observa un desarrollo de actividades industriales, de base tanto manufacturera metálica como no metálica. Por último, ambas regiones presentan una especialización en actividades deportivas y otras actividades de esparcimiento. 


\subsection{Una mirada general sobre la diversificación productiva en las regiones de Chile.}

En definitiva, algunas regiones en Chile se especializan en actividades económicas para las cuales disfrutan de ventajas comparativas, como es el caso de las regiones mineras del norte, mientras que otras se benefician de la diversificación de su base productiva, como ocurre en la Región Metropolitana. La especialización, es decir, cuando las empresas de la misma industria se ubican cerca de otras, favorece la transmisión de conocimientos intra-industria y la competencia inter-empresas, lo cual genera mayor eficiencia. Por su parte, la diversificación, es decir, cuando las empresas de distintas industrias se ubican en un espacio común, facilita el intercambio de ideas entre sectores, lo que también aumenta la eficiencia y disminuye la vulnerabilidad de la economía regional al no ser tan dependiente de un solo tipo de bienes y servicios. Tanto la especialización como la diversificación pueden potencialmente ser beneficiosas para la región en la que se ubican las empresas al verse favorecidas por los efectos de derrame de la profundización de la actividad innovadora (OCDE, 2009).

Los resultados de este trabajo muestran que en Chile no se encuentran efectos de distrito, como los que se presentan en algunas provincias de la Toscana en Italia (Becattini, 2006) o en ciertas comarcas de Valencia (Soler, 2000). Hay dos aspectos que son importantes considerar: por un lado, los niveles de especialización que se registran en Chile son más bajos que los de los casos europeos señalados anteriormente; por otro, además, en las regiones donde la concentración en pocos sectores es mayor, no hay una densidad de empresas importante.

Cabe recordar, siguiendo a Rodríguez Miranda et al. (2017, p. 52), la diferencia entre distrito y cluster:

Simplificando conceptos, podríamos decir que se trata de un modelo de distrito si el proyecto empresarial en cuestión es liderado e integrado en su mayoría por empresas locales, que forman una red densa y que son dirigidas por empresarios para los cuales el territorio no es sólo un ámbito de generación de un excedente económico sino que también es el lugar de vida, lo que confiere a los factores extraeconómicos un peso muy diferente al caso en el que la actividad es controlada por agentes externos. En el cluster... la cooperación entre empresas es también clave pero el territorio, en su componente social, es un telón de fondo y no ocupa un lugar central en la toma de decisiones del sistema productivo. El territorio es en este caso solo un espacio de apropiación de un excedente económico generado y gestionado por actores para los cuales no constituye un lugar de vida.

Como señala la OCDE (2009), en Chile, los clusters se forman naturalmente en las regiones con abundantes recursos naturales: minería en el norte, sector agrícola, forestal y pesca en el sur, y servicios financieros en Santiago. Se trata de sectores ya maduros, basados principalmente en recursos naturales, que no requieren ni incentivan el desarrollo de una fuerza de trabajo altamente cualificada ni actividad innovadora, y que, además, no movilizan recursos y activos locales. 
Además, como se apuntaba antes, en general, esa especialización sectorial es reflejo de la existencia de algunas pocas grandes empresas que operan en esas regiones y no responde a la existencia de un conjunto significativo de PYMES. Por lo tanto, atendiendo a la definición de Rodríguez Miranda et al. (2017), resulta difícil identificar en Chile modelos productivos en esos territorios que se asimilen a distritos ni a clusters.

En cualquier caso, sin duda en Chile existen aglomeraciones productivas de empresas dedicadas a la misma actividad y concentradas geográficamente, lo que propicia la creación de economías externas de escala. No obstante, en general, en las regiones donde se da este tipo de desarrollo productivo, dentro de las especializaciones principales se encuentran las actividades primarias y los servicios que éstas demandan.

Por otra parte, conviene tener presente que el análisis en este documento es a escala regional. No obstante, si bajamos al nivel sub-regional y nos centramos en las localidades y microrregiones, el turismo presenta en algunos casos rasgos de actividad de distrito. Por ejemplo, en Pucón en La Araucanía, en Puerto Natales en Magallanes o en localidades de la costa de Valparaíso como Reñaca, Concón y Maitencillo, que son localidades o microrregiones que se desarrollan y viven en torno a esa actividad productiva del turismo.

En las últimas décadas, en Chile ha habido una preocupación por promover el desarrollo de conglomerados productivos y clusters a través de la formulación de políticas y la creación de una institucionalidad de apoyo para fortalecer el trabajo colaborativo entre empresas, sector público y otras organizaciones de fomento productivo. Por lo tanto, resulta pertinente estudiar si efectivamente se producen relaciones de cooperación entre las empresas de los sectores que se aglomeran en determinados territorios del país. Los datos de este trabajo no permiten ahondar en estas cuestiones. Sin embargo, en el marco de este proyecto de investigación, se ha realizado un estudio, de próxima publicación, en el que se analizan la cooperación y las relaciones que se producen entre empresas de sectores específicos. No obstante, como nos recuerdan Rodríguez Miranda et al. (2017, p. 55):

no deberíamos esperar que en todos los territorios se produzcan desarrollos productivos del tipo cluster o del tipo distrito. La masa crítica de empresas e instituciones pueden ser limitantes que señalen dónde pueden ocurrir estos desarrollos y dónde no, además de que estos procesos siempre tienen un componente endógeno que no hace fácil su desarrollo en cualquier lugar. 


\section{Conclusiones.}

A modo de reflexiones finales, en este apartado se presentan algunos de los principales desafíos en términos de política de desarrollo productivo para Chile y sus regiones.

En primer lugar, resulta fundamental diversificar la base productiva de la economía chilena. Como se ha visto, la base de exportaciones se especializa principalmente en materias primas, fundamentalmente en el cobre. La sobre-dependencia de los recursos naturales puede comprometer el potencial de desarrollo de las regiones, y del país en su conjunto, en el largo plazo, pues esto hace que la economía sea vulnerable a cambios repentinos en los precios internacionales de dichos productos y a fluctuaciones de la demanda.

En las últimas décadas, Chile ha desarrollado fuertes competencias y tecnologías en los sectores basados en recursos naturales. No obstante, ese desarrollo no se ha traducido hasta el momento en una transferencia de conocimiento y productividad hacia otros sectores de actividad económica. En este sentido, se requiere potenciar el desarrollo de nuevos productos en sectores emergentes e incentivar a las regiones a movilizar sus recursos endógenos (OCDE, 2009).

Al respecto, la OCDE (2009) sugiere que, dada la importante producción de bienes primarios, el sector manufacturero se encuentra claramente subutilizado en Chile. Se trata de un sector que, por sus características, tiene la potencialidad de desarrollar bienes de mayor valor agregado para la economía chilena. Por un lado, el sector manufacturero tiene muchos vínculos con otros sectores de la economía. Además, a través de la tecnología y la fuerza de trabajo capacitada, es capaz de transferir nuevas tecnologías hacia la economía y aumentar la eficiencia de otras industrias. Pese a ello, en la actualidad no existen en el país regiones altamente especializadas en los productos manufacturados.

Por otra parte, en segundo lugar, es necesario agregar valor a los sectores productivos existentes. Como se ha señalado, una economía vigorosa está basada en una fuerza de trabajo altamente capacitada y una permanente actividad innovadora. Para ello, se requiere inversión en capital humano y en investigación y desarrollo, lo que permitirá aumentar la productividad de los sectores ya existentes.

Como señala la OCDE (2009), los países más desarrollados han sido exitosos al transformar la producción de bienes simples en bienes más complejos y de mayor valor agregado en la cadena de producción. Esta situación representa actualmente un desafío para la economía chilena. Es claro en sectores ya maduros como el del cobre, pero también en las regiones especializadas en la agricultura. En este sentido, las áreas rurales deben desarrollar los sectores manufacturero y de servicios como complementos a la actividad agrícola existente, promoviendo bienes de mayor valor agregado, mediante vínculos con los centros urbanos y con otros sectores de la economía. Esta 
diversificación productiva de las áreas rurales reduciría su vulnerabilidad e incertidumbre frente a cambios repentinos en los precios agrícolas y a pérdidas en la producción como resultado de inclemencias climáticas. No obstante, para ello se necesita mejorar el capital humano, la infraestructura y la disponibilidad de servicios, entre otros, en las localidades rurales.

Por otra parte, en las áreas metropolitanas, especialmente en Santiago, los bienes y servicios de mayor valor agregado no deberían limitarse a los servicios financieros. En este sentido, Santiago puede aprovechar oportunidades de desarrollo en sectores de alto nivel tecnológico como aparatos químicos, farmacéuticos y médicos (OCDE, 2009).

Finalmente, en tercer lugar, es necesario aprovechar las potencialidades de las economías de aglomeración urbana. Como es sabido, las economías de aglomeración urbana generan una serie de beneficios (economías crecientes de escala, vínculos "hacia delante" y "hacia atrás" entre empresas, cercanía a los proveedores y clientes y a los mercados de trabajo, etc.) a las empresas e industrias que se localizan en un determinado territorio. Sin embargo, hay ciertos factores que pueden limitar el potencial de las economías de aglomeración urbana.

En Chile, gran parte de la actividad económica se concentra en Santiago debido a los beneficios asociados a estas economías de aglomeración. No obstante, los costos de congestión, el alto grado de desigualdad y segregación espacial dentro del área metropolitana, y los problemas de contaminación ambiental pueden suponer un obstáculo a las economías de escala, a la cohesión y la estabilidad sociales y al desarrollo sustentable de Santiago. Desafíos similares, aunque con distintos énfasis, aparecen también en otras ciudades de Chile, como Valparaíso y Concepción. Será, por tanto, imprescindible atender a estos aspectos para aprovechar plenamente las potencialidades de las economías de aglomeración urbana. 


\section{Bibliografía y referencias documentales}

Alburquerque, F. (2002). Desarrollo Económico Territorial. Guía para agentes. Sevilla: Instituto de Desarrollo Regional, Fundación Universitaria.

Alburquerque, F. (2004). Desarrollo Económico local y descentralización en América Latina. Revista de la CEPAL, 82, 157-171.

Argumedo, P. y A. Zuleta (2018). Desarrollo económico regional y especializaciones productivas en El Salvador. El Salvador: Fundación Salvadoreña para el Desarrollo Económico y Social (FUSADES).

Becattini, G. (2006). Vicisitudes y potencialidades de un concepto: El distrito industrial. Economía Industrial, $359,21-27$.

DIRECON (2018). Comercio exterior de Chile. Reporte anual 2017. Santiago: Dirección General de Relaciones Económicas Internacionales, Ministerio de Relaciones Exteriores.

Frigolett, H. (2013). Economías regionales en Chile: desigualdad y heterogeneidad. Documentos de trabajo RIMISP $n^{\circ}$ 12, Serie Estudios Territoriales. Santiago de Chile: RIMISP - Centro Latinoamericano para el Desarrollo Rural.

Llisterri, J. J. y C. Pietrobelli (2011). Los sistemas regionales de innovación en América Latina. Washington: Banco Interamericano de Desarrollo.

OCDE (2009). Estudios territoriales de la OCDE. Chile. París: Organización para la Cooperación y el Desarrollo Económicos.

Rodríguez, Adrián, Pablo Galaso, S. Goinheix, et al, (2017). Especializaciones productivas y desarrollo económico regional en Uruguay. Instituto de Economía. Serie Documentos de Trabajo DT 07/2017. Montevideo: IECON, Universidad de la República.

Servín, B. y F. Masi (2018). Especializaciones productivas y desarrollo económico regional del Paraguay. Asunción: Centro de Análisis y Difusión de la Economía Paraguaya (CADEP).

Soler, V. (2000). Verificación de las hipótesis del distrito industrial: Una aplicación al caso valenciano. Economía industrial, 334, 13-23.

Vázquez Barquero, A. (1993). Política económica local. La respuesta de las ciudades a los desafios del ajuste productivo. Madrid: Pirámide.

(1999). Desarrollo, redes e innovación. Lecciones sobre desarrollo endógeno. Madrid: Pirámide.

(2002). Endogenous Development. Londres: Routledge.

(2005). Las nuevas fuerzas del desarrollo. Barcelona: Antoni Bosch.

(2008). Desarrollo policéntrico del territorio. En Facultad de Ciencias Económicas y Empresariales, UAM. Mimeografía. Madrid.

Vergara, P. (2004). ¿Es posible el desarrollo endógeno en territorios pobres y socialmente desiguales? Ciencias Sociales Online, 1(1), 37-52. 
Números anteriores:

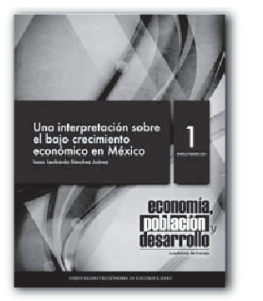

Economía, población y desarrollo.
Cuadernos de trabajo №1

Enero-Febrero 2011
Una interpretación sobre el bajo

crecimiento economico en México
Isaac Leobardo Sánchez Juárez

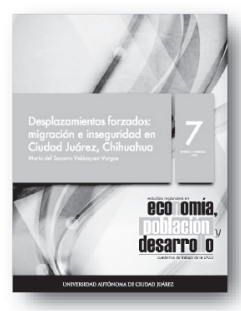

Economia, población y desarroll

Cuadernos de trabajo $\mathrm{N}$ -
Encro-Fcbrcro 2012

Desplazamientos forzados
migración e inseguridad

Ciudad Juárez, Chihuahua
Maria del Socorro Velázquez Varga

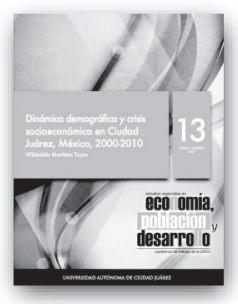

Economiá, población y desarrollo

de trabajo $N$

Dinámica demográ́fica y crisis
socieconómica en Ciudad Juáre Mexico, 2000-2010

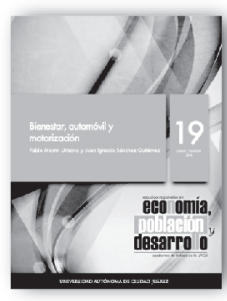

Economía, población y desarroll Enero - Febrero 2014 Bienestar, automóvil y motorización
Pablo Martín Urbano y Miosánchez Gutiérrez

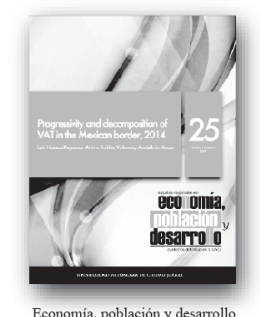

Cuadernos de trabajo No $_{0}$
Conomia,

Encro - Febrero 2015

Progressivity and decomposition of
VAT in the Mexican border, 2014 Abdelkim Araar

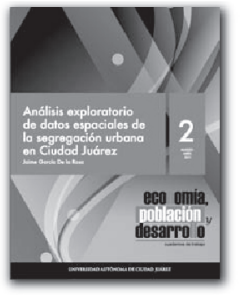

Economía, población y desarrollo.
Cuadernos de trabajo № 2

Marzo-Abril 2011

espaciales de la segregacón

Jaime Garcia De la Rosa

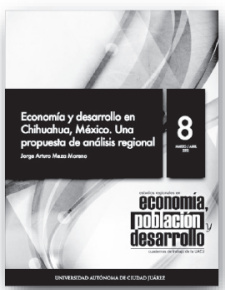

Economia, población y desarrollo

Cuadernos de trabajo №7

Economía y desarrollo en

propuesta de análisis regiona

Jorge Arturo Meza Moreno

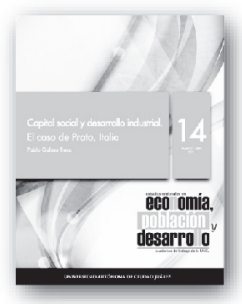

Economía, población y desarrollo

Marzo - Abri1 2013

Capital social y desarrollo

Pablo Galaso Reca

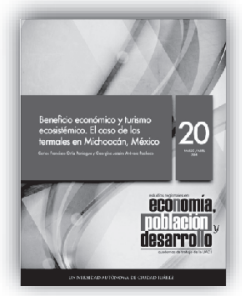

Economia, población y desarrollo

Marzo - Abril 2014

Beneficio económico y turismo

enico. El caso de las ter
en Michoacán, Mésico

arlos Franciseo Ortiz Paniagu

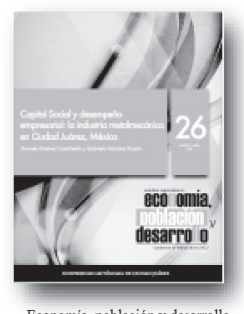

Economía, población y desarrollo

Cuadernos de trabajo № 26
Marzo - Abril 2015

Capital Social y desempeño empresa
la industria metalmecánica en

a industria metalmecánica en
Ciudad Juárez, México

Ramsés Jiménez Castañeda y
Gabriela Sáncez Bazán
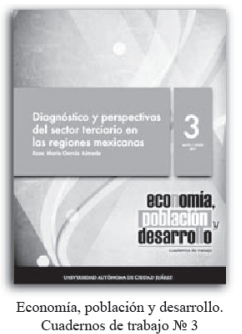

Diagnóstico y perspectivivas

regiones mexicanas
rosa Mária Garcia Almad

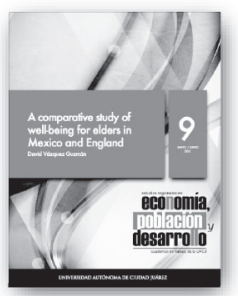

Economia, población y desarrollo

Cuadernos de trabajo № 9
Mayo - Junio 2012

A comparative study of

Mexico and England
David Vázquez Guzmán

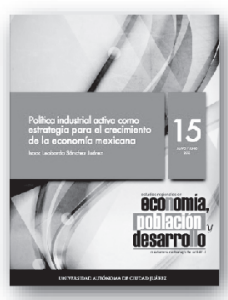

Economia, población y desarroll

Madernos de trabajo
Mayo - Junio 2013

Politica ind ustrial activa como

strategia para el crecimiento

Isaac Lcobardo Ś́nexicana
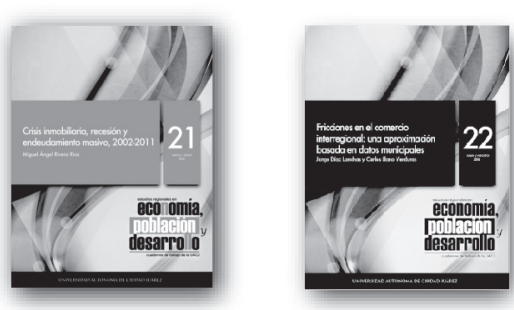

Economia, población y desarrollo

Cuademos de trabajo
Mayo - Junio 2014

Crisis inmobiliaria, recesión y
adeudamiento masivo, $2002-2011$

Miguel Ángel Rivera Rios

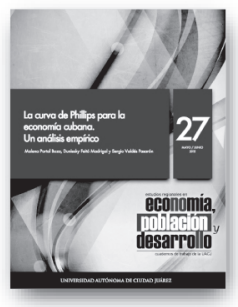

Economia, población y desarrollo

Cuadernos de trabajo № 27

a curva de Phillips para

economía cubana.

Malena Portal Boza, Duniesky Feitó

Economía, población y desarrollo.
Cuadernos de trabsio

julio-Agosto 201

Los indices IDH y FGT en la

mera década del siglo XX

Economía, población y decarrollo

Cuadernos de trabajo №
Julio - Agosto 2012

Political competition and the

edistribution in a federation

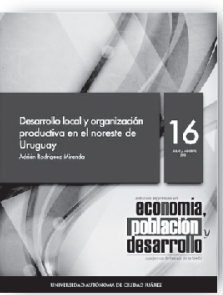

Economía, población y desarrollo

Cuadernos de trabajo №
Julio - Agosto 2013

Desarrollo local y organización
productiva en el noroeste de Urugu

Economía, población y desarrollo

Julio - Agosto 2014

Ficciones en el comercio

basada en datos municipales
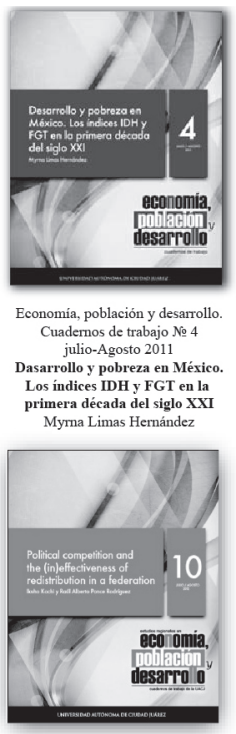

Jorge Diaz Lanchas y Carlos Llano Verduras
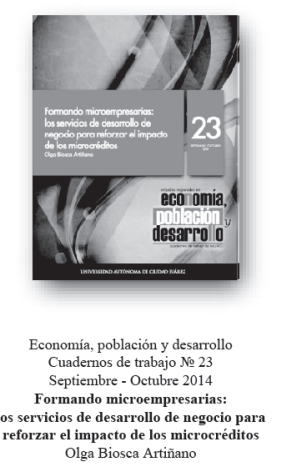

Cuadernos de trabajo № 24

El crecimiento de las regiones

el paradigma del desarrollo

divergente. Un marco térico
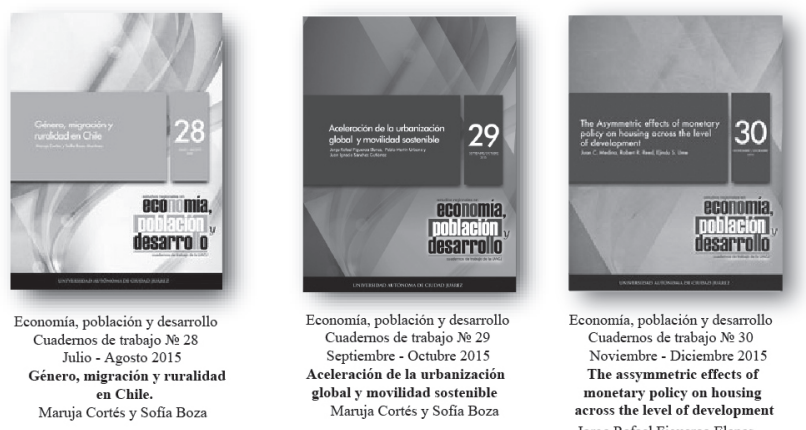

conomía, población y desarrol

Cuadernos de trabajo № 30

The assymmetric effects of

monetary policy on housing

Jorge Rafael Figueroa Elenes,

Juan Ignacio Sánchez Gutiérrez 
Números anteriores:
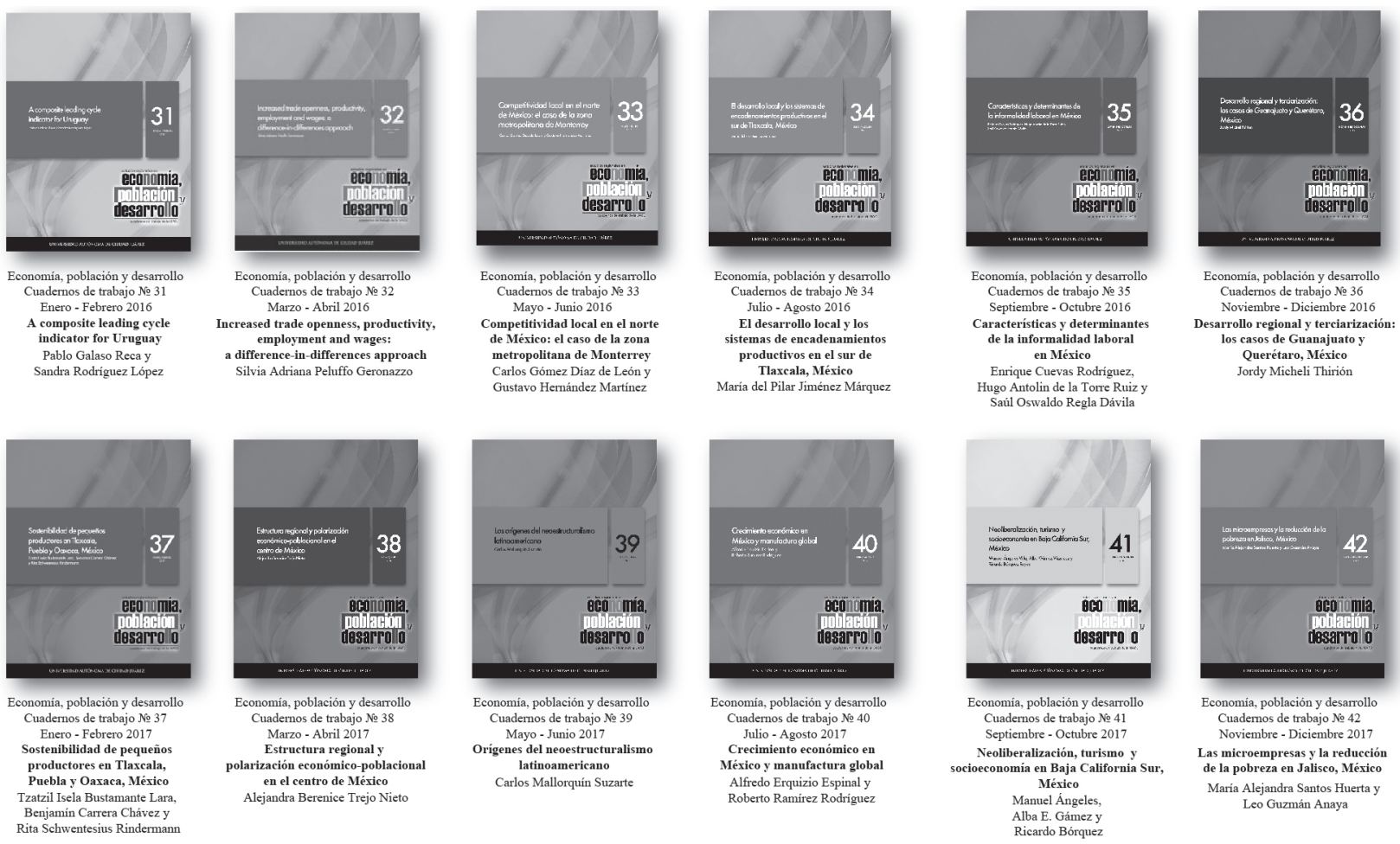

Cuadernos de trabajo № 42 Noviembre - Diciembre 2017 Las microempresas y la reducción
de la pobreza en Jalisco, México Maria Alcjandra Santos Hucetta y eo Guzman Anaya
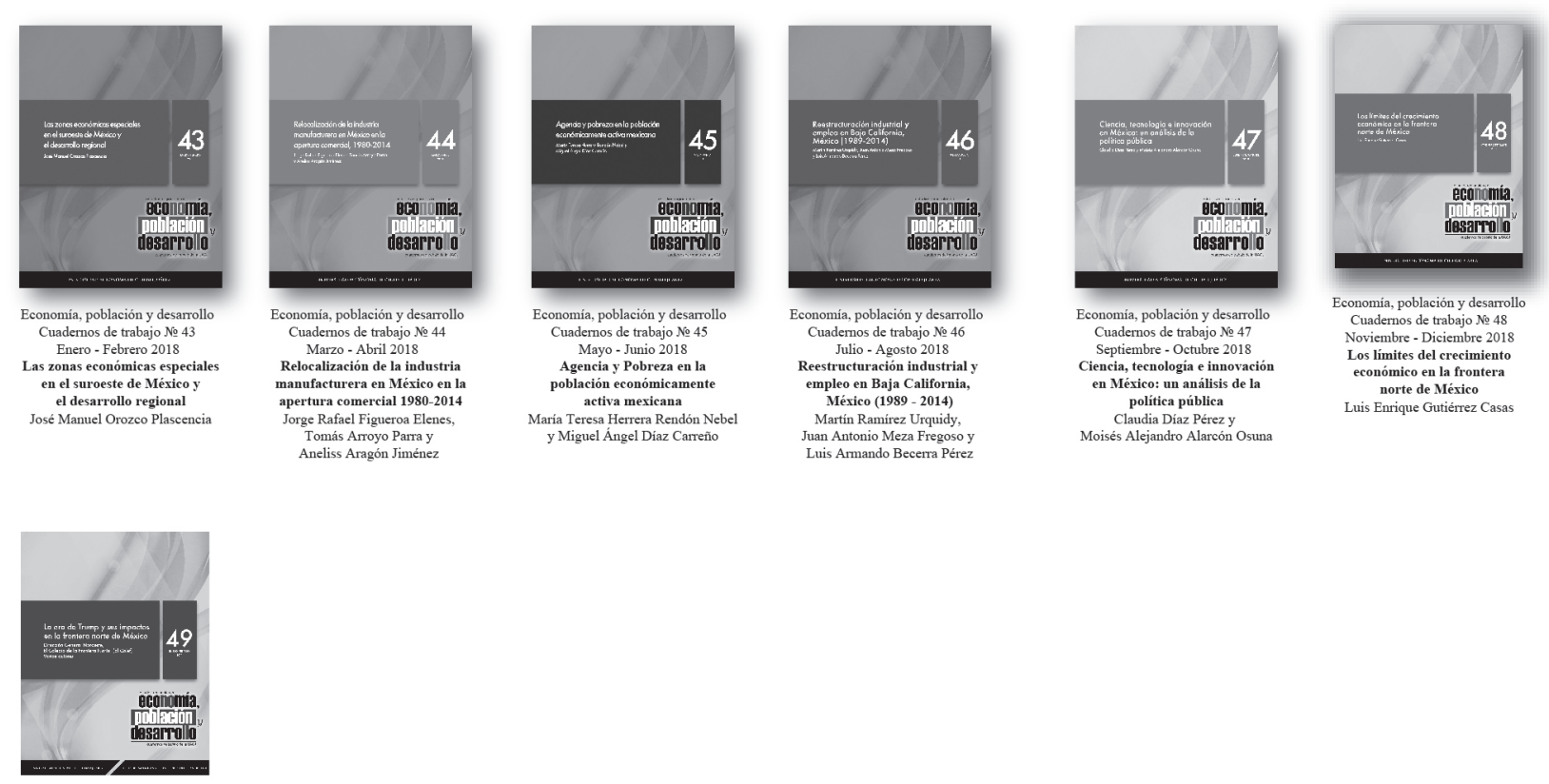

Economía, población y desarroll Cuadernos de trabajo №
Enero - Febrero 2019 Enero - Febrero 2019
La era de Trump y sus impactos
en la froptera norte de Mésico en la firección General de México Varios autores 


\section{$\rightarrow$ Normas Editoriales}

\section{Para el documento general:}

Tipo de letra: Times New Roman.

Tamaño: 11 puntos.

Interlineado: 1.5 espacios.

Títulos y subtítulos:

El texto principal en 11 puntos. Títulos 12 puntos (en resaltado). Subtítulos 11 puntos. Cada título y subtítulo deberá numerarse bajo el siguiente orden: $1,1.1,2,2.1,2.2 \ldots$

La extensión máxima de los cuadernos de trabajo será de 40 cuartillas.

La primera vez que se emplee una sigla en el texto se especificará primero su equivalencia completa y después la sigla.

\section{Hoja de presentación:}

Título:

14 puntos, centrado, resaltado.

Nombre de autor(es):

12 puntos

Resumen y abstract:

Debe incluir resumen en español y abstract (diez puntos), no mayor a 250 palabras

Palabras clave:

Incluir entre tres y cinco palabras clave, en español e inglés

Referencia del autor o autores:

Institución de adscripción, grado académico y líneas-grupos de investigación que desarrolla y a los que pertenece.

\section{Sistema de referencia de citas:}

Harvard-APA

Las citas bibliográficas en el texto deberán incluir entre paréntesis sólo el apellido del autor, la fecha de publicación y el número de página; por ejemplo: (Quilodrán, 2001: 33).

\section{Notación en sección de bibliografía y fuentes de información:}

Se deberá incluir al final del texto. Toda referencia deberá estar mencionada en el texto o notas de pie de página.

Cada referencia iniciará con el primer apellido o los apellidos, luego el nombre del autor, y después, entre paréntesis, el año de publicación seguido de un punto. Ejemplos:

Se deberá incluir al final del texto. Toda referencia deberá estar mencionada en el texto o notas de pie de página.

Cada referencia iniciará con el primer apellido o los apellidos, luego el nombre del autor, y después, entre paréntesis, el año de publicación seguido de un punto. Ejemplos:

Artículo:

Ros, Jaime (2008). “La desaceleración del crecimiento económico en México desde 1982”, en Trimestre Económico, vol. 75, núm. 299, pp. 537-560.

Libro:

Villarreal, René (2005). Industrialización, competitividad y desequilibrio externo en México. 
Un enfoque macroindustrial y financiero (1929-2010), México, Fondo de Cultura Económica. Capítulo de libro:

Castillo, Manuel Ángel (2003). "La política de inmigración en México: un breve recuento", en Manuel Ángel Castillo, Alfredo Lattes y Jorge Santibáñez (coords.), Migración y fronteras, Tijuana, El Colegio de la Frontera Norte / Asociación Latinoamericana de Sociología / El Colegio de México, pp. 425-451.

\section{Notas de pie de página:}

Se utilizarán para hacer indicaciones complementarias, aclaraciones o ampliación de una explicación. La notas de pie de página en Times New Roman, 10 puntos.

\section{Tipología de imágenes dentro del texto:}

Cuadro

Gráfica

Diagrama

Mapa

Figura

Todas las imágenes deben ser numeradas y mencionadas dentro del texto. A toda imagen debe incluirse la fuente.

Las indicaciones de la imagen: tipo y número de imagen, título de imagen y fuente se escriben en 10 puntos. En el texto poner como imagen los mapas, figuras, gráficas y diagramas -con el ánimo de no perder el formato realizado por el autor.

\section{Ecuaciones y fórmulas:}

Si se utilizan ecuaciones o fórmulas deberá utilizarse el editor de ecuaciones de Word y numerarse.

\section{Envío de trabajos}

Los trabajos deben ser enviados a la dirección de correo: lgtz@uacj.mx. Con el Dr. Luis Enrique Gutierrez Casas, editor de esta publicación.

La aceptación de cada colaboración dependerá de la evaluación de dos dictaminadores especialistas en la materia que se conservarán en el anonimato, al igual que el autor (autores) para efectos de la misma. 


\section{$\rightarrow$ Editorial Guidelines}

\section{For General Document:}

Font type: Times New Roman.

Size: font size 11 .

Paragraph: 1.5 line spacing.

Titles and subtitles: Main text font size 11. Titles font size 12 (Bold). Subtitles font size 11.

Each title and subtitle should be numbered in the following order: 1, 1.1, 2, 2.1, 2.2...

The maximum length of the workbooks will be 40 pages.

The first time an abbreviation is used in the text will be specified first complete equivalence and then stands.

\section{Front cover:}

Title:

Font size 14, centered, Bold.

Author name(s):

Font size 12.

Abstract:

It should include abstract in Spanish and abstract (font size 10), no more than 250 words.

Keywords:

Include three to five keywords, in Spanish and English.

Reference of author:

Institution of affiliation, academic degree and line-developed by research groups and belonging.

\section{Bibliographical appointment system:}

Harvard-APA

Citations in the text should include between parentheses only the author's name, publication date and page number, for example:

(Quilodrán, 2001: 33).

\section{Notation about Bibliography section and Information fonts:}

Should be included at the end of the text. All references must be mentioned in the text or footnotes page.

Each reference starts with the first name or last name, then the name of the author, and then, in parentheses, the year of publication followed by a period. Examples:

Article:

Ros, Jaime (2008). "La desaceleración del crecimiento económico en México desde 1982”, en Trimestre Económico, vol. 75, núm. 299, pp. 537-560.

Book:

Villarreal, René (2005). Industrialización, competitividad y desequilibrio externo en México. Un enfoque macroindustrial y financiero (1929-2010), México, Fondo de Cultura Económica.

Book chapter:

Castillo, Manuel Ángel (2003). "La política de inmigración en México: un breve recuento”, en Manuel Ángel Castillo, Alfredo Lattes y Jorge Santibáñez (coords.), Migración y fronteras, Tijuana, El Colegio de la Frontera Norte / Asociación Latinoamericana de Sociología / El Colegio de México, pp. 425-451. 


\section{Footnotes:}

Must be used to make additional indications, clarification or expansion of an explanation. The footnotes must be in Times New Roman, font size 10.

\section{Image typology inside text:}

Picture

Graph

Diagram

Map

Figure

All images must be numbered and mentioned in the text, should include the source image. The indications of the image: type and number of image, image title and source are written in 10 font size. In the text set as image maps, figures, graphs and charts-with the intention of not losing the formatting by the author.

\section{Equations and Formulae:}

When using equations or formulas should be used in Microsoft Word equation editor and numbered.

\section{Paper sending}

Entries must be sent to the email address: lgtz@uacj.mx. With Dr. Luis Enrique Gutiérrez Casas, editor of this publication.

Acceptance of each collaboration will depend on the evaluation of two examiners skilled in the art to be kept anonymous, like the author(s) for the same purposes. 
Esta obra se editó y terminó de imprimir en Ciudad Juárez, Chihuahua, México 
Cuadernos de Trabajo de la Universidad Autónoma de Ciudad Juárez, número 50, marzo - abril de 2019

\section{Director y editor}

Dr. Luis Enrique Gutiérrez Casas

\section{Comité editorial}

Sección internacional

Dra. Sofía Boza Martínez (Universidad de Chile, Chile)

Dra. Olga Biosca Artiñano (Glasgow Caledonian University, Reino Unido)

Dra. Ángeles Sánchez Díez (Universidad Autónoma de Madrid, España)

Dr. Thomas Fullerton Mankin (University of Texas at El Paso, Estados Unidos)

Dr. Adrián Rodríguez Miranda (Universidad de la República, Uruguay)

Dra. Ikuho Kochi (Kanazawa University, Japón)

\section{Sección local}

(Universidad Autónoma de Ciudad Juárez)

Dra. Myrna Limas Hernández

Dra. Rosa María García Almada

Dr. Raúl Alberto Ponce Rodríguez

Dr. Isaac Leobardo Sánchez Juárez

Dr. Héctor Alonso Barajas Bustillos

Dr. Juan Carlos Medina Guirado

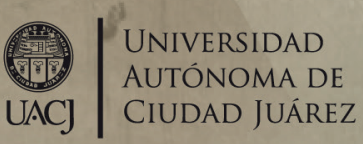

Universidad Autónoma de Ciudad Juárez Cuadernos de Estudios Regionales en Economía, Población y Desarrollo ISSN 2007-3739

Cuerpo Académico de Estudios Regionales en Economía, Población y Desarrollo

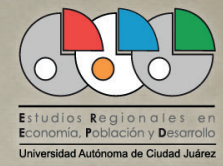

www.estudiosregionales.mx

UACJ

CUERPOS

ACADÉMICOS

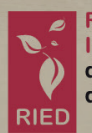

\section{Red}

beroamerican de Estudios del Desarrollo

Publicación afiliada a la Red Iberoamericana de Estudios del Desarrollo

(c) Universidad Autónoma de Ciudad Juárez Avenida Plutarco Elías Calles \#1210, Fovissste Chamizal Ciudad Juárez, Chih., México. www.uacj.mx 